\title{
Common Factors of Commodity Prices
}

\section{Simona Delle Chiaie ${ }^{1}$, Laurent Ferrara $^{2} \&$ Domenico Giannone ${ }^{3}$}

\author{
September 2017, WP \#645
}

\begin{abstract}
In this paper we extract latent factors from a large cross-section of commodity prices, including fuel and non-fuel commodities. We decompose each commodity price series into a global (or common) component, block-specific components and a purely idiosyncratic shock. We find that the bulk of the fluctuations in commodity prices is well summarised by a single global factor. This global factor is closely related to fluctuations in global economic activity and its importance in explaining commodity price variations has increased since the 2000 s, especially for oil prices. ${ }^{4}$
\end{abstract}

Keywords: Commodity prices, Dynamic factor models, Forecasting

JEL classification: C51, C53, Q02.

\footnotetext{
${ }^{1}$ European Central Bank, simona.dellechiaie@ecb.europa.eu

2 Banque de France, laurent.ferrara@,banque-france.fr

${ }^{3}$ Federal Reserve Bank of New York and CEPR, domenico.giannone@ny.frb.org

${ }^{4}$ We are grateful to Christiane Baumeister, Daniele Caratelli, Luca Guerrieri, Raju Huidrom, Lutz Kilian, Michele Lenza, Evgenia Passari and Robert Vigfusson for helpful comments and suggestions. We would also like to thank seminar participants at the World Bank, at the International Symposium of Forecasting 2013 in Seoul,at the Vienna Workshop "High-dimensional Time Series in Macroeconomics and Finance 2015", at the 2nd Annual Conference of the International Association for Applied Econometrics 2015, the Bank of England-Banque de France Workshop on International Macroeconomics 2015 and the 23rd Annual Conference of the Society for Computational Economics 2017 for their useful comments.

Working Papers reflect the opinions of the authors and do not necessarily express the views of the Banque de France, the European Central Bank, the Eurosystem, the Federal Reverse Bank of New York or the Federal Reserve System. This document is available on publications.banque-france.fr/en
} 
In this paper we analyse the degree of co-movement in international commodity returns by studying a broad range of commodities that are representative of the global market. In doing so, we estimate a dynamic factor model with a block structure to decompose each commodity price series into a global (or common) component, block-specific components related to specific commodity markets and a purely idiosyncratic shock. The distinction between global, block-specific and idiosyncratic components allows for the presence of shocks of different nature, having distinct consequences on the crosscorrelation between commodity prices. We find that there is a single global factor driving the bulk of commodity price fluctuations. The global factor is persistent and follows the major expansion and contraction phases in the international business cycle with the largest declines following recession periods. It is also strongly related to measures of economic activity, suggesting a close link with demand factors. This is further corroborated by the fact that the global factor has homogenous effects on all markets and hence limited effects on relative prices. Since the start of the new millennium, the relevance of the global factor has increased, especially for oil. We compute model-based historical decompositions of commodity price changes and we find that the global factor explains a large fraction of commodity price fluctuations during episodes typically associated with changes in global demand conditions, such as the world economic expansion that started around 2003 and the steep contraction during the Great Recession. By contrast, block components explain most of the fluctuations in commodity prices during episodes conventionally associated with supply or other commodity-specific shocks. We perform an out-of-sample validation of the model. We find that the factor model performs well in forecasting commodity prices and indices of commodity prices, in particular at short horizons.

\section{Historical decompositions of commodity prices: The price boom of the 2000 s}
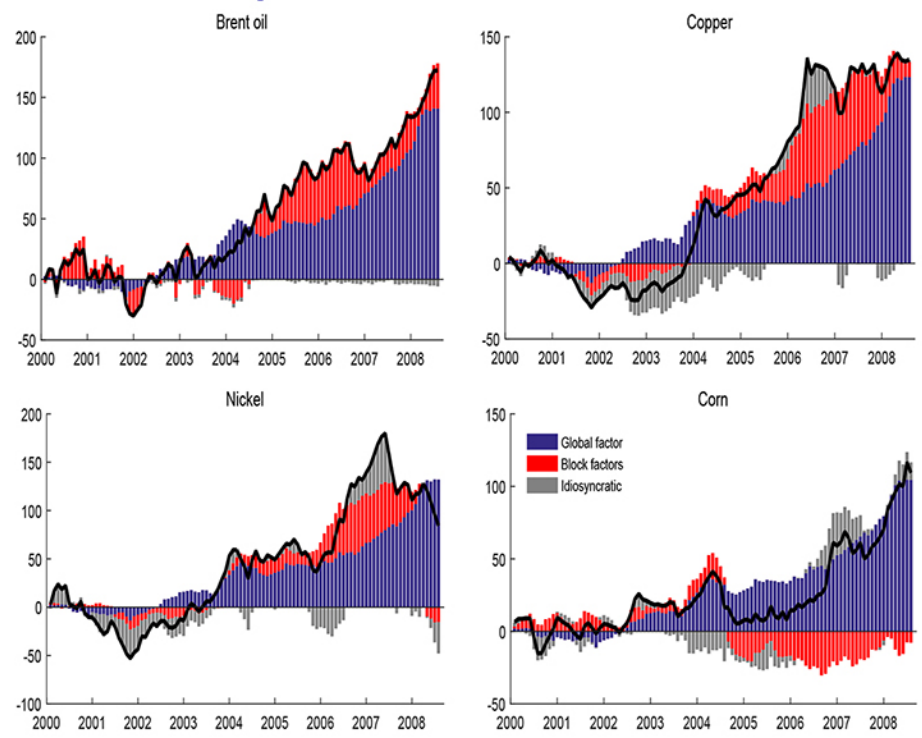

Note: The figure reports the historical decomposition of the price for a selected group of energy, metal and food commodities, showing the cumulative effects at each point in time of global (blue), block-specific (red) and idiosyncratic (grey) shocks from January 2000 to July 2008, (Delle Chiaie, Ferrara \& Giannone, BdFeco WP 2017) 


\title{
Les facteurs communs aux prix des matières premières
}

\begin{abstract}
RÉSUMÉ
Dans ce papier, nous estimons des facteurs communs à partir d'une grande base de données de prix de matières premières. Nous décomposons chaque série de prix de matières premières en une composante globale (commune), une composante spécifique au type de matières premières et un choc purement idiosyncratique. Nous trouvons que les principales fluctuations des prix des matières premières sont bien résumées par un seul facteur commun. De plus, ce facteur commun est fortement relié aux évolutions de l'activité économique mondiale et son importance dans l'explication des variations de prix de matières premières s'est accrue depuis les années 2000, notamment en ce qui concerne le prix du pétrole.

Mots-clés : prix des matières premières, modèles à facteurs dynamiques, prévision.

Les Documents de travail reflètent les idées personnelles de leurs auteurs et n'expriment pas nécessairement la position de la Banque de France, de la Banque Centrale Européenne, de l'Eurosystème, de la Federal Reverse Bank of New York ou du Federal Reserve System. Ce document est disponible sur publications.banque-france.fr
\end{abstract}




\section{Introduction}

Primary commodities, in the form of raw or partially processed goods, have been historically a key input of international trade. Despite the importance of the primary sector has declined over time both across advanced and emerging economies, primary commodities continue to have a central role in manufacturing processes and in the food supply. As such, primary commodities like crude oil, wheat or copper have been traditionally case examples of traded goods across borders and still account for a significant share of international trade (more than one-third according to data from the Wold Bank). Most primary commodities are now bought and sold around the globe in well-organized markets where physical and derivative trading take place. Like stock exchanges, commodity exchanges feature institutional and regulatory frameworks that ensure valuable protection to commodities traders; they reduce credit risks and provide liquid instruments to hedge (or speculate) against unexpected price fluctuations. The high level of market liquidity is reflected by the fact that purely financial transactions currently outpace transactions in which physical delivery actually occurs.

As far as financial asset returns are concerned, it has been long recognized that they are characterised by a high degree of co-movement, especially asset prices (see, for a recent survey, Connor and Korajczyk (2010)). This feature is at the heart of the asset pricing theory and suggests that a few underlying factors might explain the bulk of the fluctuations in asset returns. Recently, Miranda-Agrippino and Rey (2015) also find evidence of international co-movement in the returns of a large panel of risky assets.

A few research studies as well as more informal narratives indicate that there are also commonalities in international commodity prices. The presence of a strong co-movement in the price of a broad range of different commodities might seem odd given that there is a wide variety of goods involved, with a number of specific factors affecting both supply and demand in each market. Nevertheless, commodity prices may co-move because of common macroeconomic factors, such as changes in current and expected future aggregate demand (see, e.g. Pindyck and Rotemberg (1993)). A booming or slumping global economy affects the demand for industrial commodities and, via income effects, shifts the demand of a broader group of commodities, moving prices in the same direction. Focusing on the oil market, an influential strand of the literature has stressed the role of world business cycle conditions for oil price fluctuations (see, e.g. Barsky and Kilian (2002), Kilian (2009), Peersman and Van Robays (2009), Lippi and Nobili (2012)).

In this paper we analyse the degree of co-movement in international commodity returns by studying a broad range of commodities that are representative of the global market. In doing so, we estimate a dynamic factor model with a block structure to decompose each commodity price series into a global (or common) component, block-specific components related to specific commodity markets and a purely idiosyncratic shock. The distinction between global, local and idiosyncratic components allows for the presence of shocks of different nature, having 
distinct consequences on the cross-correlation between commodity prices.

We find that there is a single global factor driving the bulk of commodity price fluctuations. The global factor is persistent and follows the major expansion and contraction phases in the international business cycle with the largest declines following recession periods. It is also strongly related to measures of economic activity, suggesting a close link with demand factors. This is further corroborated by the fact that the global factor has homogenous effects on all markets and hence limited effects on relative prices. Since the start of the new millennium, the relevance of the global factor has increased, especially for oil. While the importance of demand has been documented in the context of the oil market (see, literature cited above), our paper shows that the association with global demand is even stronger when looking at the common factors underlying all the commodities.

We compute model-based historical decompositions of commodity price changes and we find that the global factor accounts for a larger fraction of commodity price fluctuations in episodes typically associated with changes in global economic activity, such as the world economic expansion that started around 2003 and the steep contraction during the Great Recession. By contrast, block components explain most of the fluctuations in commodity prices during episodes conventionally associated with supply or other commodity-specific shocks. For oil prices, we found that fuel-specific factors are the main underlying sources of oil price changes that occurred before the 2000s, such as the collapse of OPEC in 1986 and the Persian Gulf War of 1990-1991. The structural analyses in the earlier works of Kilian and Murphy (2014) and Kilian and Lee (2014) support this result, showing that oil-specific demand shocks and exogenous shifts in supply were a more important determinant of the price of oil before the 2000 s.

In order to verify the robustness of the modelling strategy, we complement the in-sample analysis by performing an out-of-sample validation of the model. Overall, we find that our factor model performs well in forecasting commodity prices and aggregate indices of commodities, in particular at short horizons. In particular, the predictive performance of the global factor is higher for the group of commodities for which the historical variance explained by the global factor is larger, such as food and metals. These results are in line with other studies - focusing on the oil market - which have also found evidence that proxies of global demand have predictive power for oil prices (see, Baumeister and Kilian (2012)). Similarly, changes in commodity prices indices, in particular industrial raw materials, have been proved to improve the forecast of the price of oil, as these indices are more likely to capture shifts in the global demand for industrial commodities (see, Alquist, Kilian and Vigfusson (2013)). In this respect, our factor-based forecast is a refinement of these earlier approaches. The out-of-sample exercise also shows that for some commodities, in particular crude oil, the predictive content of the global factor has increased during the Great Recession.

Our paper is not the first that studies the co-movement in commodity prices (see, e.g. 
Alquist and Coibion (2014), Byrne et al. (2011), West and Wong (2014), Chen et al. (2014)). The focus of this earlier literature is different from ours for two reasons. First, these papers have studied commodity prices in levels instead of the returns, focusing on the co-movement at low frequencies. Second, they do not analyse simultaneously all commodity markets and look at selected groups of commodities.

The rest of this paper proceeds as follows. Section 2 presents the empirical analysis, the global factor and analyses the sources of commodity price fluctuations. Section 3 studies the predictability and the local forecasting performance of the model. Finally, Section 4 concludes.

\section{Empirical analysis}

\subsection{Data}

The data $x_{t}$ used in the estimation include the spot prices of 52 internationally traded commodities from different categories, including food, beverages, agricultural raw materials, metals and fuel commodities. The source of our data is the IMF primary commodity price database. Prices are monthly averages of daily prices and cover the sample from January 1980 to December 2015. ${ }^{1}$ Since the estimation of the model described in the next section requires covariance-stationary variables, all prices have been taken in log differences. The data have been further standardised to have a zero sample mean and a unit sample variance. The IMF primary commodity price database also includes 10 price indices and sub-indices, representing the major commodity sectors, constructed as weighted averages of individual commodity prices. The weights used for computing the indices are the commodity trade values compared to the total world trade as reported in the UN Comtrade database. It is worth noting that because the basket of the IMF database has been designed to have a set of commodities representative of the world economy, other commodity indices might have different composition and weighting schemes. For instance, the World Bank Index, which has been designed to be representative of developing countries, gives a greater weight to commodities, such as coffee, rice or palm oil that constitute important export shares of developing countries and includes commodities, such as fertilizers that are not included in the IMF index.

An interesting feature of these indices that we will exploit later in the empirical analysis is that they are built to reflect different levels of aggregation; the data set is thus characterised by a block structure summarised in Table 1. The first or global index is constructed as a weighted average of all commodity prices in the dataset, hence it represents a broad index of commodity prices. This, in turn, is divided into two main block indices which are constructed using non-fuel and fuel commodity price series, respectively. As shown in Table 1, the energy block represents about 60 percent of the overall index. The non-fuel block can then be broken

\footnotetext{
${ }^{1} \mathrm{~A}$ few series are not available from the beginning of the sample but start only in the 1990s. Maximum likelihood estimates can be adopted to deal with missing data (see, Banbura and Modugno (2014)).
} 
down into two other group indices, edibles and industrial inputs which are in turn divided into five other subcategories representing food, beverages, agricultural raw materials and metals. The fuel block index contains only one subcategory, represented by the index of crude oil prices. The full list of series used in the analysis and their descriptions are reported in Table 2 .

\subsection{Model and estimation}

The model used here is an approximate dynamic factor model for large cross-sections. This model provides a parsimonious representation of the dynamic co-variation among a set of random variables. Consider an $n$-dimensional vector of commodity returns $x_{t}=\left(x_{1 t}, \ldots, x_{n t}\right)^{\prime}$ with mean zero. Under the assumption that $x_{t}$ has a factor representation, each series $x_{i t}$ is the sum of two unobservable components, a common component - capturing the bulk of cross-sectional co-movements - and an idiosyncratic component reflecting specific shocks or measurement errors:

$$
x_{i t}=\lambda_{i} f_{t}+e_{i t}
$$

where $f_{t}=\left(f_{1 t, \ldots,}, f_{r t}\right)^{\prime}$ is an $r$-dimensional vector of common pervasive factors affecting all commodities; $\lambda_{i}=\left(\lambda_{i 1, \ldots} \lambda_{i r}\right)^{\prime}$ is a vector of factor loadings where each of the element in $\lambda_{i}$ measures the effect of the common factors to commodity $i$; $e_{i t}$ is the idiosyncratic component which is assumed to be non-pervasive and weakly correlated across commodities. The common factors $f_{t}$ and the idiosyncratic component $e_{i t}$ are uncorrelated at all leads and lags. Note that if $\lambda_{i}$ is similar across commodities, then $f_{t}$ has a limited impact on relative prices. We model the common factors as following an autoregressive process of finite-order:

$$
A(L) f_{t}=u_{t}
$$

where $A(L)=I-A_{1} L-\ldots A_{p} L^{p}$ an $(r \times r)$ filter of finite length $p$ with roots outside the unit circle, and $u_{t}$ is a Gaussian white noise, $u_{t} \sim$ i.i.d $\mathcal{N}\left(0, I_{r}\right)$.

We further assume that the model has a block structure that represents a parsimoniuos way to model the local correlation among idiosyncratic components. This implies decomposing $e_{i t}$ into factors that are specific to groups or blocks of commodities and a purely idiosyncratic component:

$$
e_{i t}=\sum_{j=1}^{K} \gamma_{i j} g_{j t}+v_{i t}
$$




$$
\gamma_{i j}= \begin{cases}\neq 0 & \text { if } i \in j \\ 0 & \text { otherwise }\end{cases}
$$

where $g_{j t}$ is (an $r_{b}$-dimensional vector) of block-factors; $\gamma_{i j}$ are block-factor loadings and $v_{i t}$ is the purely idiosyncratic disturbance. The block factors $g_{j t}$ and the purely idiosyncratic component $v_{i t}$ are assumed to follow an autoregressive process of finite-order:

$$
\begin{gathered}
g_{j t}=\phi_{j} g_{j t-1}+w_{j t} \\
v_{i t}=\rho_{i} v_{i t-1}+\varepsilon_{i t}
\end{gathered}
$$

with $w_{j t} \sim i . i . d \mathcal{N}(0,1)$ and $\varepsilon_{i t} \sim i . i . d \mathcal{N}\left(0, \sigma_{i}^{2}\right)$.

Principal components are obtained as a special case of our estimates, under the following assumptions:

$$
\left\{\begin{array}{l}
\gamma_{i j}=0, \forall i, j \\
\rho_{i}=0, \forall i \\
\sigma_{i}^{2}=\bar{\sigma}, \forall i
\end{array}\right.
$$

Maximum likelihood estimation is implemented using the Expectation Maximization (EM) algorithm as in Doz et al. (2012). The algorithm consists of two steps. In the first step (M-step), the algorithm is initialised by computing principal components and the model parameters are estimated by OLS regression treating the principal components as if they were the true common factors. Since these estimates have been proved to be an asymptotically consistent estimator of the true common factors (see, Forni et al. (2000), Stock and Watson (2002a, 2002b) and Bai (2003)), the initialisation is good when the cross-section dimension is large. In the second step, given the estimated parameters, an updated estimate of the common factors is obtained using the Kalman smoother. If we stop at the second step, we have the two-step estimates of the common factors studied by Doz et al. (2011). Maximum likelihood is obtained by iterating the two steps until convergence, taking at each step into account the uncertainty related to the fact that factors are estimated.

It is worth noting that in order to keep the number of parameters limited, we have assumed a parsimonious parameterisation of the idiosyncratic dynamics. However, Doz et al. (2012) have shown that under the approximate factor structure (i.e. pervasive factors and limited cross-sectional correlation among idiosyncratic components), maximum-likelihood estimates of the model are robust to misspecification of the cross-sectional and time series correlation of the idiosyncratic components. Moreover, the estimates have been shown to be robust also 
to non gaussianity. In this respect, the estimator is a quasi-maximum likelihood estimator in the sense of White (1982).

A growing body of research has applied the quasi-maximum likelihood estimator to extract common factors from large cross-sections for a variety of empirical applications. For instance, this method has become a popular tool for now-casting (see, for surveys, Banbura, Giannone and Reichlin (2011), Banbura, Giannone, Modugno and Reichlin (2013) and recently, Luciani (2014)). Banbura, Giannone and Lenza (2015) applied this approach to perform conditional forecasts and scenario analyses; Brave and Butters (2011) constructed a high-frequency indicator of national financial conditions published by the Federal Reserve Bank of Chicago. This method has also been used for structural analyses, as done, for example, in Reis and Watson (2010) and Luciani (2015).

\subsection{How many factors and blocks?}

We begin our analysis by estimating common and block-specific components using likelihoodbased methods described in the previous section. Note that the factor estimates are computed using the commodity returns in $x_{t}$ which excludes the higher level aggregates represented by the commodity indices. In this way, we avoid introducing - by construction - collinearity in the panel data since commodity indices are linear combinations of commodity prices.

We determine the number of blocks to include in the model by following the structure of our database. In macroeconometrics, data are typically organised either by country, sectoral origin or economic concept, therefore the empirical literature on factor models has mostly looked at the composition of the data set to have guidance on the extraction of the blocks. For instance, Forni and Reichlin (2001) distinguish between European and national components to study the potential degree of output stabilization deriving from federal policies; using Bayesian estimation methods, Kose, Otrok, and Whiteman (2003) study the sources of the international business cycle by extracting world, country and regional components; Banbura, Giannone and Reichlin (2011) use blocks of nominal and real variables for the purpose of nowcasting real economic activity; Miranda-Agrippino and Rey (2015) decompose fluctuations in risky assets into global, regional and asset-specific components. Like these papers, we extract local factors that reflect the composition of the panel data which in our case is based on different categories of commodities (see, Table 1). Therefore, we extract two main block factors (fuel and nonfuel), two sub-block factors (food and beverages and industrial inputs) and finally, five group factors (food, beverages, agricultural raw materials, metals and oil).

To determine the optimal number of common factors from the observed data, we take into account the trade-off between the goodness-of-fit and the loss in parsimony that arises from increasing the number of factors. In order to do so, we use a modified version of the information criterion in Bai and $\mathrm{Ng}$ (2002). These authors derive a penalty function to select the optimal number of factors in approximate factor models when factors are estimated by 
principal components. Nevertheless, the statistical approach of Bai and Ng (2002) can be extended to any consistent estimator of the factors provided that the penalty function is derived from the correct convergence rate. For the quasi-maximum likelihood estimator used in this paper, Doz et al. (2012) show that the convergence rate for the factor estimates is given by $C_{N T}^{* 2}=\min \{\sqrt{T},(N /(\log N))\}$. Hence, a modified version of the Bai and $\mathrm{Ng}(2002)$ information criterion (IC) is given by:

$$
I C^{*}(r)=\log \left(V\left(r, F_{(r)}\right)\right)+r g(N, T), g(N, T)=\left(\left(\log \left(C_{N T}^{* 2}\right)\right) /\left(C_{N T}^{* 2}\right)\right)
$$

where $r$ is the number of common factors, $F_{(r)}$ denotes the estimated factors, $V\left(r, F_{(r)}\right)$ is the sum of squared idiosyncratic components divided by $N T$ and finally, $g(N, T)$ represents the penalty function for over-fitting. ${ }^{2}$ For our panel data, the statistics in Table 3 selects the model with one common factor since this provides the smallest value of the IC statistics. From here on, we will refer to this single common factor in commodity prices as the global factor.

\subsection{Empirical results}

\section{The Global Factor}

The global factor estimated over the full sample is shown in Figure 1 along with the IMF global index of commodity prices. The latter is a linear combination of commodity prices with weights given by trade values. In contrast, in the case of the global factor, weights are given by the estimated factor loadings. While cross-sectional averages, such as the IMF index, tend to approximate well the global factor in case of limited cross-correlation among idiosyncratic disturbances (see, for instance Forni and Reichlin, (1998)), in practical applications, simple averages may have a substantial component of noise arising from the idiosyncratic component. Figure 1 shows that the global factor and the IMF broad index of commodity prices resemble each other, ${ }^{3}$ however they differ in their second-order properties. A visual inspection of the two series suggests that while the broad index of commodity prices is characterised by swift fluctuations, for instance those associated with the oil price shocks in the early 1990s, the global factor is a smoother and more persistent series.

Particular attention should clearly be paid to what the global factor captures. Recent studies on commodity prices based on principal components have related the estimated common factors to macroeconomic and financial data by means of correlations (see, e.g. Byrne et al. (2011), Chen et al. (2014) and West and Wong (2014)). Other studies in the financial literature, in particular Tang and Xiong (2012), have associated the co-movement among com-

\footnotetext{
${ }^{2}$ The information criterion has been recently applied to the quasi-maximum likelihood estimator by Coroneo et al (2016).

${ }^{3}$ The correlation coefficient between the two series is 0.63 .
} 
modity prices with the growing participation of financial speculators in commodity markets in the 2000s. A large body of research, however, has not found substantive evidence that speculation had an effect on commoditiy prices, at least for the oil market (see, for instance Fattouh et al (2012), Kilian and Murphy (2014), Kilian and Lee (2014), Juvenal and Petrella (2014)).

A natural conjecture is that the global factor, being a pervasive shock affecting a large cross-section of commodity prices, might capture movements in global economic activity. Indeed, a booming or slumping global economy might affect the demand for a broad group of commodities, directly via the impact on industrial commodities and indirectly via general equilibrium effects. If so, one would expect the estimated factor loadings of the global factor to be positive such that the sign of the response of commodity prices to global factor changes is alike across commodities. Figure 2 shows that the factor loadings are mostly positive and the largest responses are found for food and metals, such as sunflower oil, soybeans, corn and copper. Second, we find that the global factor tends to co-move with real indicators of global economic activity. To illustrate this, Figure 3 plots the global factor along with the index of world real economic activity proposed by Kilian (2009). This measure, based on dry cargo ocean freight rates, has been explicitly developed to capture shifts in the demand for industrial commodities associated with periods of high and low real economic activity. In order to make the comparison meaningful, the global factor is expressed here in year-on-year growth rates. The figure shows that the two indices are positively correlated and follow the major expansion and contraction phases in the international business cycle over the period considered with the largest declines following recession periods. The fast macroeconomic expansion that characterised the world economy since the earlier 2000s, and in particular, some emerging market economies, is also captured by the two series. Looking at the most recent period, we observe that both measures indicate a weakening in the global economy, which is consistent with the decline in commodity prices observed at the end of our sample. ${ }^{4}$ Likewise, Figure 4 compares the global factor with monthly indicators of industrial production for three selected geographical areas as provided by the CPB Netherlands Bureau for Economic Policy Analysis. Yet, the correlation between these series is clearly positive and quite high. Finally, we check to what extent the global factor might capture fluctuations in oil prices. To do so, Figure 5 shows the global factor with the growth rate of the price of Brent crude oil together with estimates of global demand and supply of oil. Three observations can be made. First, the correlation between the global factor and oil prices is mildly positive over the full sample

\footnotetext{
${ }^{4}$ As a robustness check, we show in appendix the global factor extracted from commodity prices deflated by the US CPI (see Figure 13). As a matter of fact, in a standard microeconomic model of demand and supply, the commodity price in the vertical axis is expressed in real terms. Hence, it may be more appropriate to use real commodity prices since the aim is to capture the changes in the real price induced by shifts of the demand curve along the supply curve. However, we have estimated the model both using real and nominal prices and none of the results of the paper appeared to be sensitive to this transformation. This might reflect the fact that our sample does not include high inflation periods, such as the Great inflation of the 70s.
} 
but the correlation between the two series has increased in the last decade. Second, the global factor and the price of oil are positively correlated with measures of world consumption of oil. Third, the spikes in the price of oil that coincided with some exogenous events in the oil market such as the Persian Gulf War, the Venezuela crisis which was followed by the Iraq invasion in 2003 are not associated with similar variations in the global factor. Rather, these appear to be associated with important negative shifts in the supply of oil.

\section{Sources of commodity price fluctuations}

In this section we study the relative importance of global and block-specific factors in explaining the variations in commodity prices. Notice that a model-based variance decomposition can also be derived for the commodity indices in our data set. Let $y_{t}$ be an $m$-dimensional vector of commodity indices and $W$ be a given $(m \times n)$ matrix of weights used to compute the indices, then the variance-covariance matrix of $y_{t}$ is $\Sigma_{y}=W \Lambda \Sigma_{f} \Lambda / W \prime+W \Sigma_{e} W$ ' where $\Sigma_{f}$ and $\Sigma_{e}$ are the variance-covariance matrices of the factors and idiosyncratic components, respectively. Our results show that the global factor explains an important fraction of the variance, especially for non-fuel commodities, such as food and metals. In particular, this is the case for soybeans and soybean oil (for which the global factor accounts for about 50 percent of the variance) and to a lesser extent, copper, aluminum, palm and sunflower oil, maize and barley (see, Table 4). As a result, almost 70 percent of the variations in the index of non-fuel commodities can be attributed to the global factor (see, Table 5). In contrast, the bulk of the fluctuations in beverages, agricultural raw materials and fuel prices is mostly captured by block-specific shocks. However, a non-negligible fraction of their variance (about 20 percent for the price of oil) is driven by the global factor. Given the large weight attributed to oil prices in the IMF index, the fuel-specific factor explains most of the variance of the IMF index. Nevertheless, a third of its variations is due to the global factor.

To check the robustness of these results, we include a second global factor in the model. The variance decomposition reported in Table 6 and 7 shows that the variance explained by the first global factor is robust to the inclusion of a second global factor and the latter captures a small or tiny fraction of the variance. This finding supports the evidence provided by the IC statistic about the presence of a single global factor.

It is important to note that if the local correlation between the idiosyncratic components is not properly modelled, non-pervasive block variations can be confused with weak common factors leading to an incorrect inference on the number of common factors present in the data. In order to illustrate this point, we compare the estimated global and block factors of our benchmark specification $\left(M_{1}\right)$ with three common factors extracted from a factor model where the local correlation among idiosyncratic components $\left(M_{2}\right)$ is not modelled. We find that the first common factors of the two models are very much alike, the second common factor in $M_{2}$ is akin to the first block component (Non-Fuel) in $M_{1}$, while the third factor of 
$M_{2}$ is highly correlated with the Fuel block in $M_{1}$ and, to some extent, with the Food and Beverages sub-block. Visually, these correlation can be seen in Figure 8.

\section{Sub-sample analysis}

The analysis over the full sample might mask some important changes that might have happened in the commodity markets, in particular, since the start of the commodity price boom in mid-2003. In Figure 8, we report the model-based variance decomposition for all the commodity price indices over two sub-samples. We use 2003 as a break date in line with the observed increase in commodity prices. The subsample analysis confirms that the global factor explains an important fraction of the variation of non-fuel commodities before the 2000s while it has little explanatory power for oil and other fuel-commodities. Indeed, block-specific and idiosyncratic components account for the whole variation in oil prices in the first subsample. This evidence suggests that supply or other oil-specific shocks were, on average, a more important determinant of the price of oil than global demand shocks in the first part of the sample. The structural VAR analysis in Kilian and Murphy (2014) supports this interpretation showing that key historical events in the oil market over this period, such as the collapse of the OPEC cartel in 1986, the Gulf war in 1990-91 and the Venezuela crisis in 2002, mostly reflected shocks to the speculative demand of oil together with supply shifts. The model-based variance decomposition estimated over the second sub-sample indicates that the importance of the global factor has increased for all commodities since 2003. We find that the variance explained by the global factor has increased for all commodities in our sample but the increase is remarkable for oil and metals for which the share of the variance explained by the global factor raised to 40 and 60 percent, respectively. As a result, the share of the variance of the IMF index that can be attributed to the global factor has also increased from less than 10 percent to 60 percent in the period starting from 2003.

\section{Historical decompositions of commodity price changes}

In this section we present a factor-based historical decomposition of commodity price fluctuations. For reasons of space, we focus on a few key historical episodes and a small group of commodities with large trade values. First, an important event in the commodity market was the run-up in commodity prices from 2003 to mid-2008. A common view in the literature is that the fast economic expansion that characterized emerging market economies, and in particular China, caused the surge in commodity prices. In Figure 9, we decompose the price of a selected group of fuel and non-fuel commodities (i.e. Brent oil, copper, nickel and corn)

into global and block-specific factors, showing their cumulative effects at each point in time from January 2000 to July 2008. The decomposition of the price of oil in the upper panel of the chart indicates that the cumulative effect of shifts in the global factor largely explains the oil price surge in the 2000s while the fuel-specific component had a smaller role. The latter 
component is important to explain the increase in the price of oil in the early 2000s. All the historical decompositions in Figure 9 point to the global factor as the main underlying force of the surge in commodity prices in the 2000s.

In Figure 10, we look at four historical episodes in the oil market. The first two events refer to the oil price fall that followed the collapse of the OPEC cartel in 1986 and the oil price spike that occurred in response to the Iraqi invasion of Kuwait in 1990. These can be viewed as examples of price variations that are specific to the oil market and not necessarily related to changes in macroeconomic conditions. The historical decomposition shows that, in both episodes, the main factors underlying the variations in the price of oil are fuel-specific, while the global factor had clearly no role (Figure 10, panel 1 and 2). The third episode, in Figure 10, corresponds to the deep fall in the price of oil which started in mid-2008 as a result of the contraction in world economic activity. The historical decomposition indicates that the fall in oil prices was mostly due to cumulated changes in the global factor. There is also evidence that oil-specific component exerted further downward pressures on the price of oil at the end of 2008. Finally, the last panel of Figure 10 investigates the oil price fall that started in the second half of 2014. The model attributes about one-third of the oil price fall from June 2014 to December 2015 to the global factor. However, while the global factor explains most of the initial oil price fall, cumulated shifts in the fuel-specific component explained most of the variations since the end of 2014. This coincides with the decision of OPEC in November 2014 to hold production unchanged in order to put downward pressures on prices. Similar to our results, Baumeister and Kilian (2016) find that global demand was the main cause of the oil price decline from June to December 2014. The empirical findings in Baffes et al. (2015) and Groen and Russo (2015) are also consistent with ours.

\section{Predictive content of the global factor}

A growing empirical literature has used factor models estimated on panels of commodity prices for forecasting purposes. Common factors have been used to forecast commodity prices themselves (see, e.g., West and Wong (2014) and Poncela et al. (2015)) or other macrovariables such as inflation (Gospodinov and $\mathrm{Ng}$ (2013)). Other empirical studies have instead investigated whether macroeconomic and financial data have predictive power for commodity prices (see, e.g. Chen, Rogoff and Rossi (2012), Groen and Pesenti (2011)). Focusing on the price of oil, a strand of the literature has found that proxies of global demand have predictive power for commodity prices (see, Baumeister and Kilian (2012)). Similarly, changes in the spot price of industrial raw materials have been proved to improve the forecast of the price of oil, as those price changes are more likely to capture shifts in the global demand for industrial commodities (see, Alquist, Kilian and Vigfusson (2013)).

In this section we perform an out-of-sample validation of the model to verify the robust- 
ness of the modelling strategy. To this end, starting from January 2001, we estimate the model on a rolling window of 20 years of past data and compute out-of-sample forecasts of commodity prices each month from February 2001 to December 2015. The h-step ahead forecasts for individual commodity prices are iterated from the state-space representation using the Kalman filter while forecasts for aggregate commodity indices are computed as averages of the individual commodity price forecasts, weighted using their trade weights. ${ }^{5}$ After computing the sequence of the out-of-sample forecast error loss differences between the model and a naive benchmark (i.e. a constant growth model), we calculate the average loss difference as well as rolling average losses along the lines of Giacomini and Rossi's (2010) fluctuation test. This test, which is useful to study the forecasting performance of a model in a unstable environment, is based on the difference between the mean squared forecast error (MSFE) of the candidate model and the benchmark, smoothed over time with a centered rolling window of fixed size. The statistical significance of the relative performance of the model against the benchmark is then tested at each point in time using the Diebold and Mariano's (1995) test of equal predictive accuracy.

The main results of the out-of-sample forecasting exercise can be summarised as follows. First, we observe that the model performs well in predicting commodity prices and indices, especially at short horizons. At $h=1$, the model outperforms the benchmark with gains in accuracy that range from $18 \%$ for the non-fuel index to $12 \%$ for the fuel-index (see, Table 6 ). The forecasts of disaggregated commodity prices confirm that the model provides the largest accuracy gains for food and metals (for instance, copper (19\%), rice (19\%), poultry $(46 \%)$, cotton $(17 \%)$ and aluminium $(12 \%))$. However, at $h=1$, the reduction in MSFE is also marked for oil prices for which gains range between $9 \%$ and $12 \%$. Second, the predictive performance deteriorates progressively over longer horizons and at $h=12$, we cannot reject the hypothesis of equal predictive performance between the model and the benchmark. Finally, we find that the predictive ability of the model has changed over time. The evolution of the rolling relative MSFE in Figure 11 indicates that the predictability of oil and other energy commodities increased markedly in the second half of the 2000s. Indeed, from 2007 to 2011, the MSFE of the factor model improved substantially compared to the benchmark. However, given the high level of volatility, the test cannot reject the null of equal predictive accuracy. The finding of a greater predictive performance during the Great Recession is consistent with previous results showing that, for macroeconomic and financial variables, downturn periods are characterised by an increased co-movement (see, e.g. D'Agostino and Giannone (2012)).

\footnotetext{
${ }^{5}$ For each series, the variable that is predicted is: $X_{i, t+h}^{h}=100 \times \ln \left(X_{i, t+h} / X_{i, t}\right)$. The model is parameterised as in the previous sections, i.e. it is based on the assumption of a single global factor, one (block) factor for each group and category of commodity prices and one lag in the factor VAR. As a robustness check, the forecasting results are also provided for a model specification with two global factors.
} 


\section{Concluding remarks}

In this paper we have studied the co-movement in international commodity returns by looking at a broad range of commodities that are representative of the global market. In order to do

so, we have estimated a dynamic factor model with a block structure. This model allows us to extract a common factor in commodity prices - the global factor - while controlling for local correlation driven by shocks of different nature. Our results point to an important role of the global factor. This factor explains the bulk of commodity price variations and it is strongly related to changes in world economic conditions, suggesting a close link with demand factors. While the importance of demand has been documented in the context of the oil market, our paper shows that the association with global demand is even stronger when looking at the common factors underlying all the commodities.

An important implication of our paper is that to understand commodity price fluctuations it is key to analyse all commodity markets simultaneously. We identify the global factor as the one that is common to fuel and non-fuel commodities and we show that this identification is what allows to extract forces that are closely related to global demand. Historical decompositions of major commodity price changes confirm that the global factor accounts for a larger fraction of commodity price movements in episodes that coincided with changes in global activity, such as the world economic expansion that started around 2002 and the steep contraction associated with the Great Recession. By contrast, block components explain most of the fluctuations in commodity prices during episodes conventionally associated with supply or other commodity-specific shocks.

The model performs well in predicting commodity prices in real-time confirming that the high level of commonality is not an artifact due to over-fitting but is a genuine feature of the data that remains in the out-of-sample assessment, in spite of potential structural changes. 


\section{References}

[1] Alquist R. and O. Coibion (2014), Commodity Price Comovement and Global Economic Activity, NBER WP 20003.

[2] Alquist R., L. Kilian and R.J. Vigfusson (2013), Forecasting the Price of Oil, Handbook of Economic Forecasting, Volume 2A, Elsevier.

[3] Bai, J. (2003), Inferential Theory for Factor Models of Large Dimensions, Econometrica $71,135-171$

[4] Bai J. and S. Ng (2002), Determining the Number of Factors in Approximate Factor Models, Econometrica, 70, 191-221.

[5] Baffes J, M.A. Kose, F. Ohnsorge and M. Stocker (2015), The Great Plunge in Oil Prices: Causes, Consequences, and Policy Responses, World Group Policy Research Note.

[6] Bańbura M, D. Giannone and M. Lenza (2015), Conditional Forecasts and Scenario Analysis with Vector Autoregressions for Large Cross-Sections, International Journal of Forecasting 31(3), 739-756.

[7] Bańbura M., D. Giannone and L. Reichlin (2011), Nowcasting, The Oxford Handbook of Economic Forecasting.

[8] Bańbura M, D. Giannone, M. Modugno and L. Reichlin (2013), Now-casting and the real-time data flow, Handbook of Economic Forecasting 2, 195-237.

[9] Bańbura, M. and Modugno, M., (2014), Maximum likelihood estimation of factor models on data sets with arbitrary pattern of missing data, Journal of Applied Econometrics, 29(1): 199-160.

[10] Barsky R. and L. Kilian (2002), Do we really know that oil caused the Great Stagflation? A monetary alternativee, NBER Macroeconomics Annual 2001, 16, 137-183.

[11] Baumeister C. and L. Kilian (2012), Real-Time Forecasts of the Real Price of Oil, Journal of Business and Economic Statistics, 30(2), 326-336.

[12] Baumeister C. and L. Kilian (2016), Understanding the decline in the price of oil since June 2014, Journal of the Association of Environmental and resource economists, 3(1), 131-158.

[13] Bodenstein M., Erceg C. and L. Guerrieri (2011), Oil shocks and External Adjustment, Journal of International Economics 83(2), 168-184. 
[14] Brave S. and R.A. Butters (2011), Monitoring Financial Stability: A Financial Conditions index approach, Economic Perspectives Q(I), 22-43.

[15] Byrne J.P, G. Fazio and N. Fiess (2013), Primary Commodity Prices: Co-movements, Common Factors and Fundamentals, Journal of Development Economics 101: 16-26.

[16] Chen, Y.C., K.S. Rogoff and B. Rossi (2010), Can Exchange Rates Forecast Commodity Prices? The Quarterly Journal of Economics, 125(3): 1145-1194.

[17] Chen, S.L., J.D. Jackson, H. Kim and P. Resiandini (2014), What Drives Commodity Prices? American Journal of Agricultural Economics 96, 1455-1468.

[18] Connor G. and R. Korajczyk (2010), Factor Models of Asset Returns, Encyclopedia of Quantitative Finance, edited by Rama Cont, ed. Chicester: Wiley.

[19] Coroneo, L. D. Giannone and M. Modugno (2016), Unspanned Macroeconomic Factors in the Yields Curve, Journal of Business and Economic Statistics 34, 472-485.

[20] Diebold F.X. and R.S. Mariano (1995), Comparing Predictive Accuracy, Journal of Business and Economic Statistics 13, 253-263.

[21] Doz C., D. Giannone and L. Reichlin (2011), A Two Step Estimator for Large Approximate Dynamic Factor Models Based on Kalman Filtering", Journal of Econometrics 164 (2011), 188-205.

[22] Doz C., D. Giannone and L. Reichlin (2012), A Quasi-Maximum Likelihood Approach for Large, Approximate Dynamic Factor Models, The Review of Economics and Statistics, 94(4): 1014-1024

[23] D'Agostino A. and D. Giannone (2012), Comparing Alternative Predictors Based on Large-Panel Factor Models, Oxford Bulletin of Economics and Statistics, 74(2), 306-326.

[24] Fattouh, B., L. Kilian and L. Mahadeva (2012). The Role of Speculation in Oil Markets: What Have we Learned so Far? Energy Journal, 34(3), 385-394.

[25] Forni, M., M. Hallin, M. Lippi and L. Reichlin (2000), The Generalized Dynamic Factor Model: Identification and Estimation, The Review of Economic and Statistics 82, 540554 .

[26] Forni, M. \& Reichlin, L. (1998), Let's Get Real: A Factor Analytical Approach to Disaggregated Business Cycle Dynamics, Review of Economic Studies, Wiley Blackwell, vol. $65(3)$, pages $453-73$.

[27] Forni M. and L. Reichlin (2001), Federal policies and local economies: Europe and the us. European Economic Review, 45(1):109- 134, January 2001. 
[28] Giacomini R. and B. Rossi (2010), Forecast Comparisons in Unstable Environments, Journal of Applied Econometrics, 25, 595-610.

[29] Groen, Jan J.J., Pesenti, Paolo A., (2010), Commodity Prices, Commodity Currencies, and Global Economic Developments. NBER Working Paper 15743.

[30] Groen, J. and P. Russo (2015). Is Cheaper Oil Good News or Bad News for the US Economy? Liberty Street Economics, June 2015.

[31] Gospodinov, N. and S. Ng (2013),Commodity prices, convenience yields and inflation. Rev. Econ. Stat. 95, 206-219.

[32] Juvenal L. and I. Petrella (2014), Speculation in the Oil Market. Journal of Applied Econometrics, 30(4), 621-649.

[33] Kilian, L. (2009), Not All Oil Price Shocks Are Alike: Disentangling Demand and Supply Shocks in the Crude Oil Market, American Economic Review, 99(3), June 2009, 10531069 .

[31] Kilian, L and D.P. Murphy (2014), The Role of Inventories and Speculative Trading in the Global Market for Crude Oil, Journal of Applied Econometrics, 29(3), April 2014, $454-478$.

[35] Kilian, L. and T.K. Lee (2014). Quantifying the Speculative Components in the Real Price of Oil: The Role of Global Oil Inventories, Journal of International Money and Finance, 42, 71-87.

[36] Kose M. A, C. Otrok, and C.H. Whiteman (2003). International Business Cycles: World, Region, and Country-Specific Factors, American Economic Review, vol. 93(4), pages 1216-1239, September.

[37] Lippi F. and A. Nobili (2012), Oil and the Macroeconomy: A Quantitative Structural Analysis, Journal of European Economic Association, vol. 10(5), 1059-1083.

[38] Luciani, M. (2015), Monetary Policy and the Housing Market. A Structural Factor Analysis, Journal of Applied Econometrics 30(2), 199-218.

[39] Luciani M. and L. Ricci (2014), Nowcasting Norway, International Journal of Central Banking 10(4), 215-248.

[40] Miranda-Agrippino S. and H. Rey (2015), World Asset Markets and the Global Financial Cycle, NBER WP No. 21722.

[41] Nakov A. and A. Pescatori (2009), Oil and the Great Moderation, The Economic Journal, vol. 120(543), 131-156. 
[42] Peersman G. and I. Van Robays (2009), Oil and the Euro Area Economy, Economic Policy, vol 24, 603-651.

[43] Pindyck R.S and J.J Rotemberg (1990), The Economic Journal 100(403), 1173-1189.

[44] Poncela, P., E. Senra and L.P. Sierra (2015). The predictive content of co-movement in non-energy commodity price changes, mimeo.

[45] Reis R. and M.W. Watson (2010), Relative Goods' Prices, Pure Inflation and the Phillips Correlation, American Economic Journal: Macroeconomics 2(3), 128-157.

[46] Stock J. H. and M. W. Watson (2002a), Forecasting using Principal Components from a Large Number of Predictors, Journal of American Statistical Association 97, 147-162.

[47] Stock J. H. and M. W. Watson (2002b), Macroeconomic Forecasting Using Diffusion Indexes, Journal of Business and Economics Statistics 20, 147-162.

[48] Tang, K. and W. Xiong (2012). Index Investment and Financialization of Commodities, Financial Analysts Journal 68, 54-74.

[39] West K.D. and K.F. Wong (2014), A factor model for co-movements of commodity prices, Journal of International Money and Finance 42, 289-309.

[50] White, H. (1982), Maximum Likelihood Estimation of Misspecified Models, Econometrica $50,1-25$. 
Figure 1: The global factor

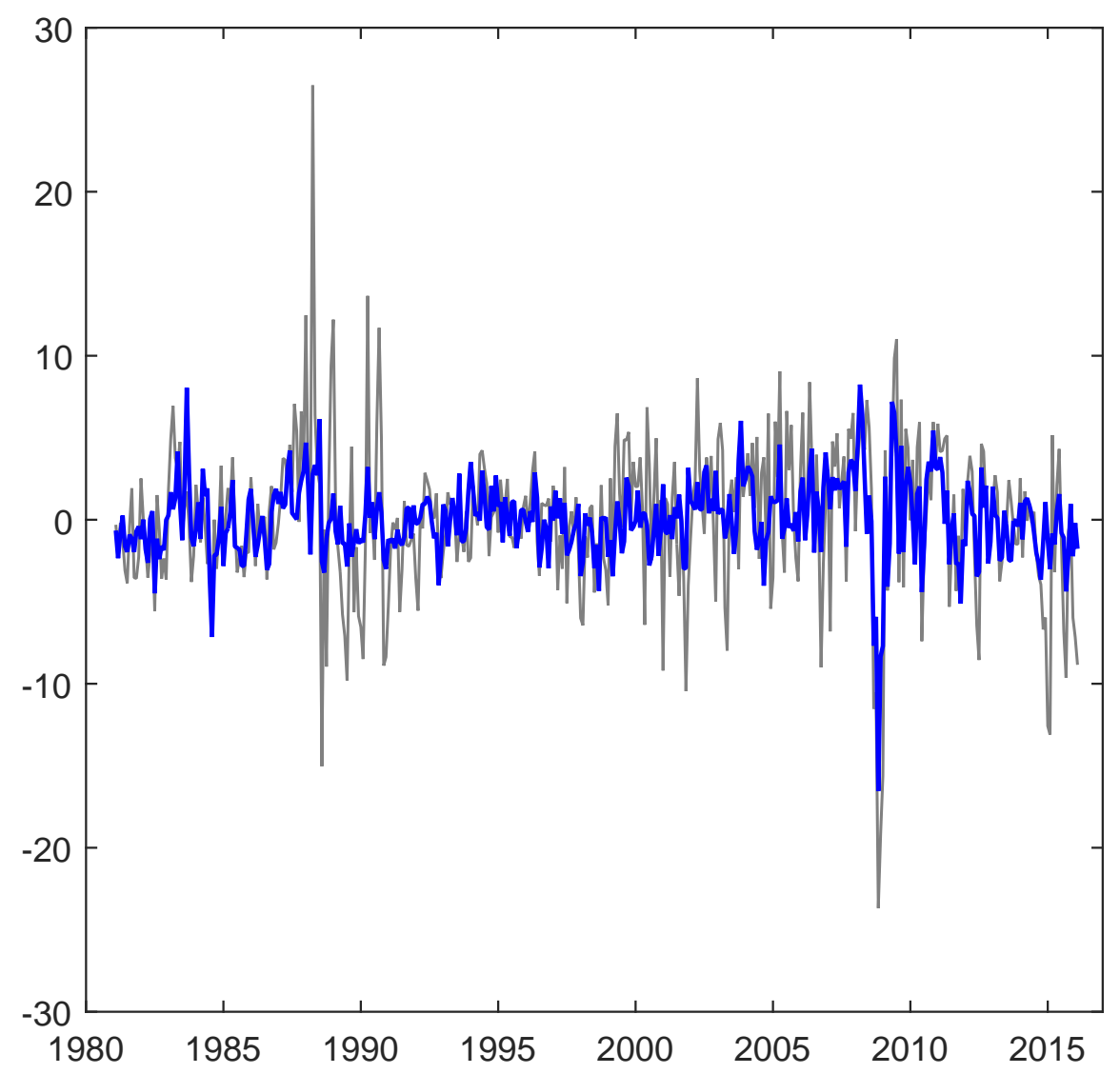

Note: The top panel of the figure shows the estimated global factor (blue line) and the IMF overall index of commodity prices (Grey line). 
Figure 2: Factor loadings associated with the global factor

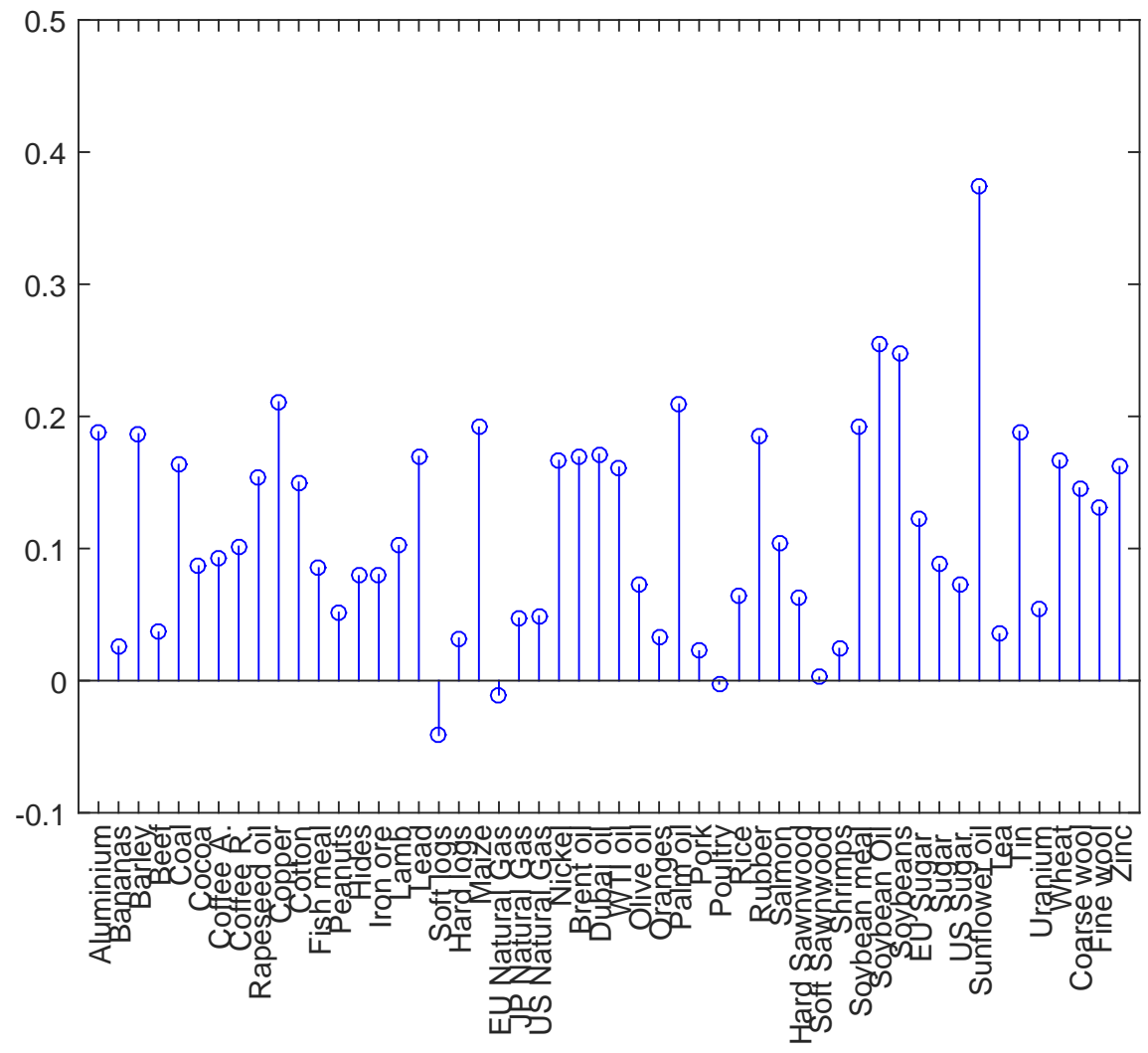


Figure 3: The global factor and the Kilian's index of economic activity

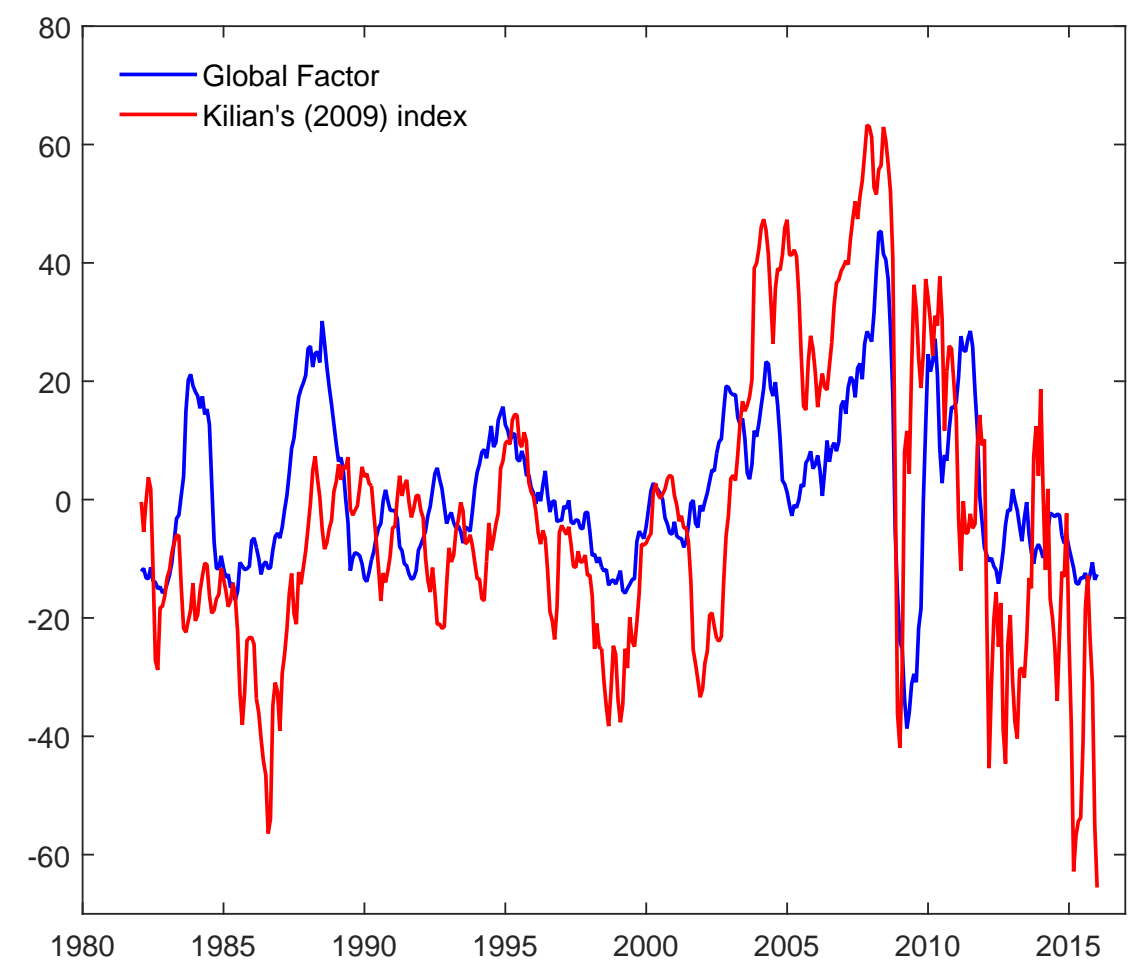

Note: The figure plots the global factor (blue line), extracted from real commodity prices and expressed in year-on-year growth rates, and the Kilian's (2009) index of real economic activity (red line). 
Figure 4: The global factor and industrial production indices

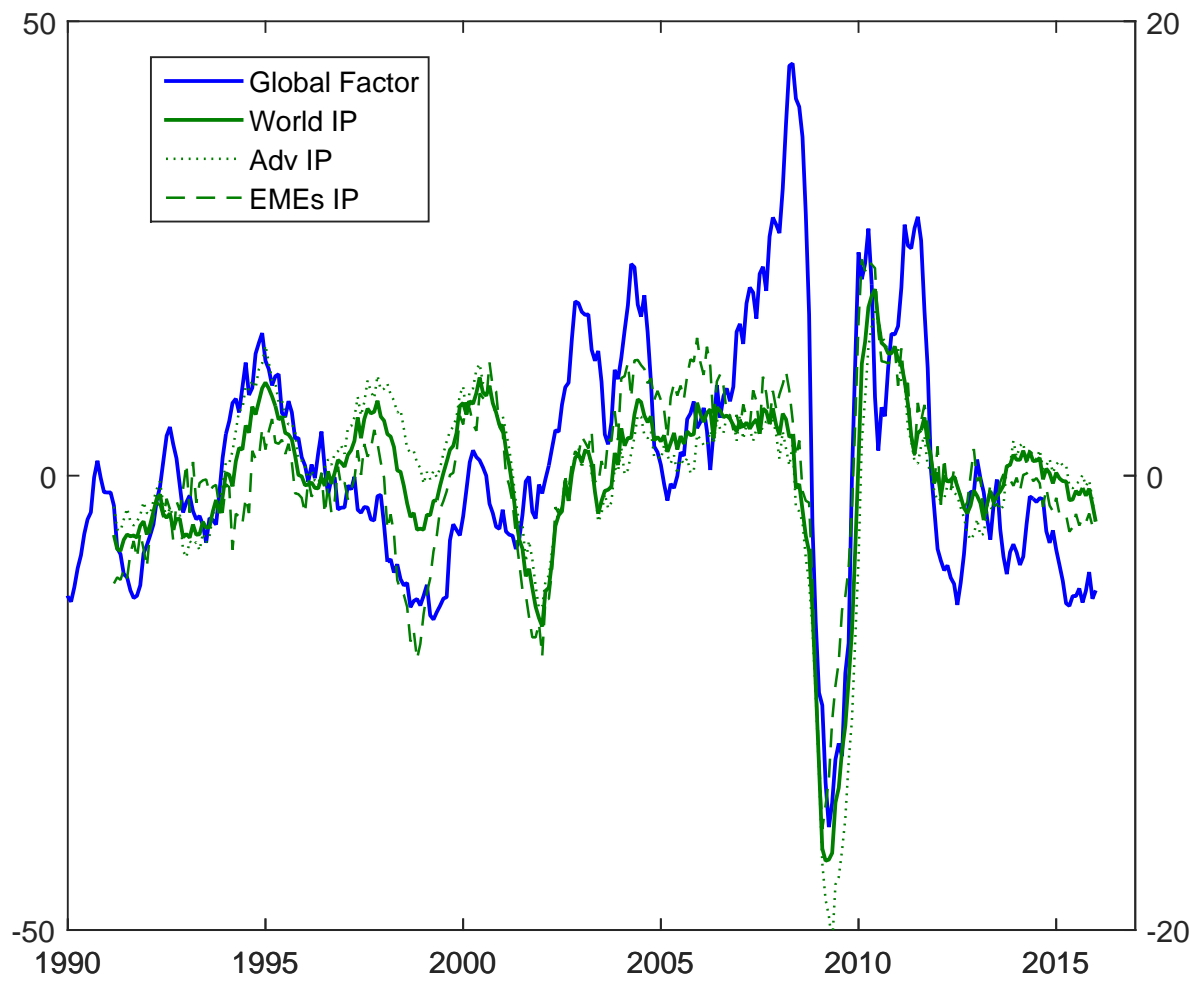

Note: The figure plots the estimated global factor (blue line) extracted from real commodity prices and measures of industrial production in selected areas as provided by the CPB Netherlands Bureau for Economic Policy Analysis. All variables are expressed in year-on-year growth rates. 
Figure 5: Oil and the Global Factor
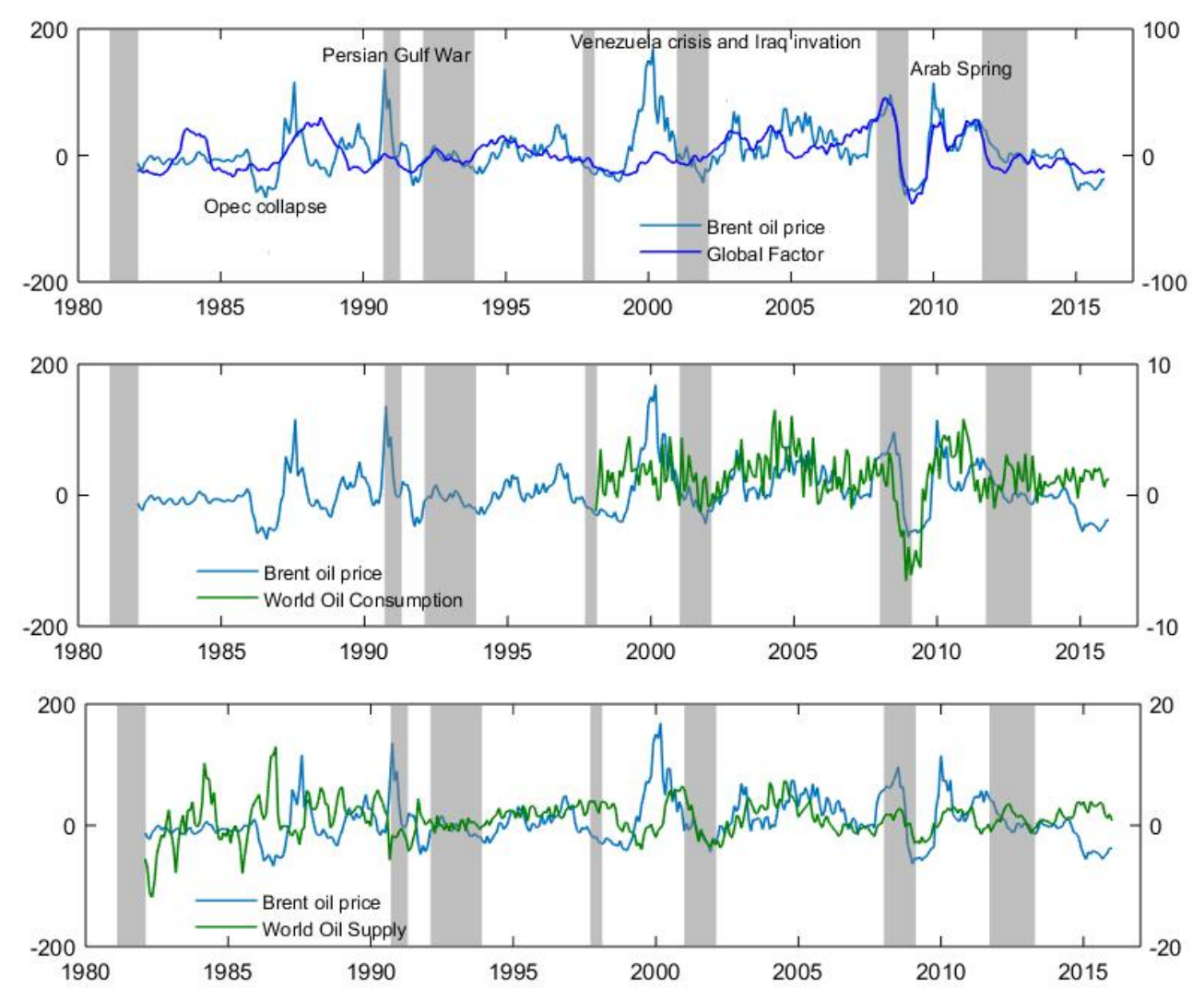

Note: All variables are expressed in year-on-year growth rates. Estimates for the world oil consumption are taken from Short-Term Energy Outlook of the Energy Information Administration (EIA) while the world crude oil production is taken from the Monthly Energy Review of EIA. The vertical bars represent periods of widespread economic slowdown. In particular, we include the early 1980s and 1990s recessions, the Asian financial crisis of 1997-1998, the recession that followed the bursting of the dot-com bubble in the 2000s, the Great Recession and, finally, the latest euro area recession starting in the third quarter of 2011. 
Figure 6: Variance explained by the first two global factors

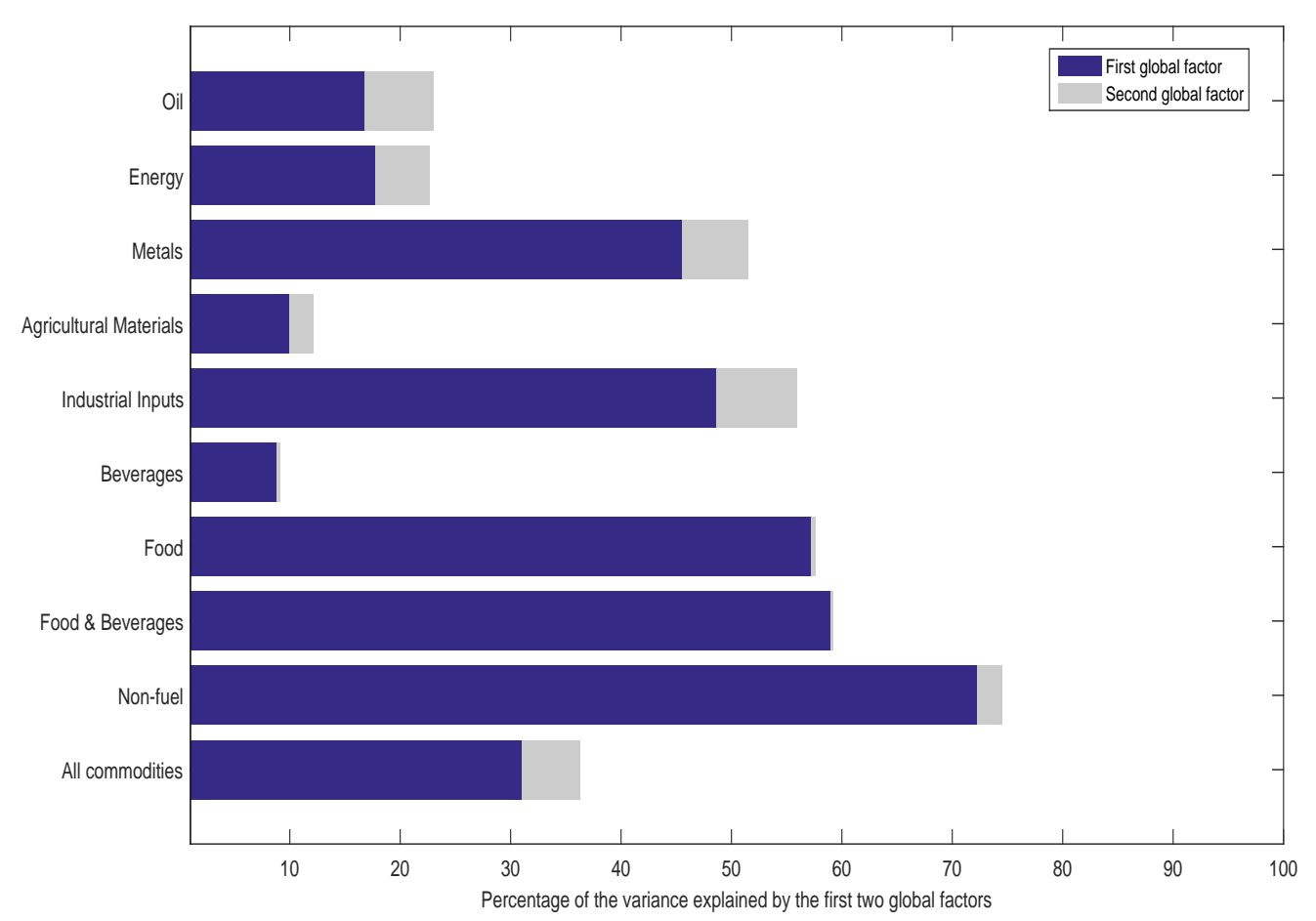


Figure 7: Variance explained by the first two global factors

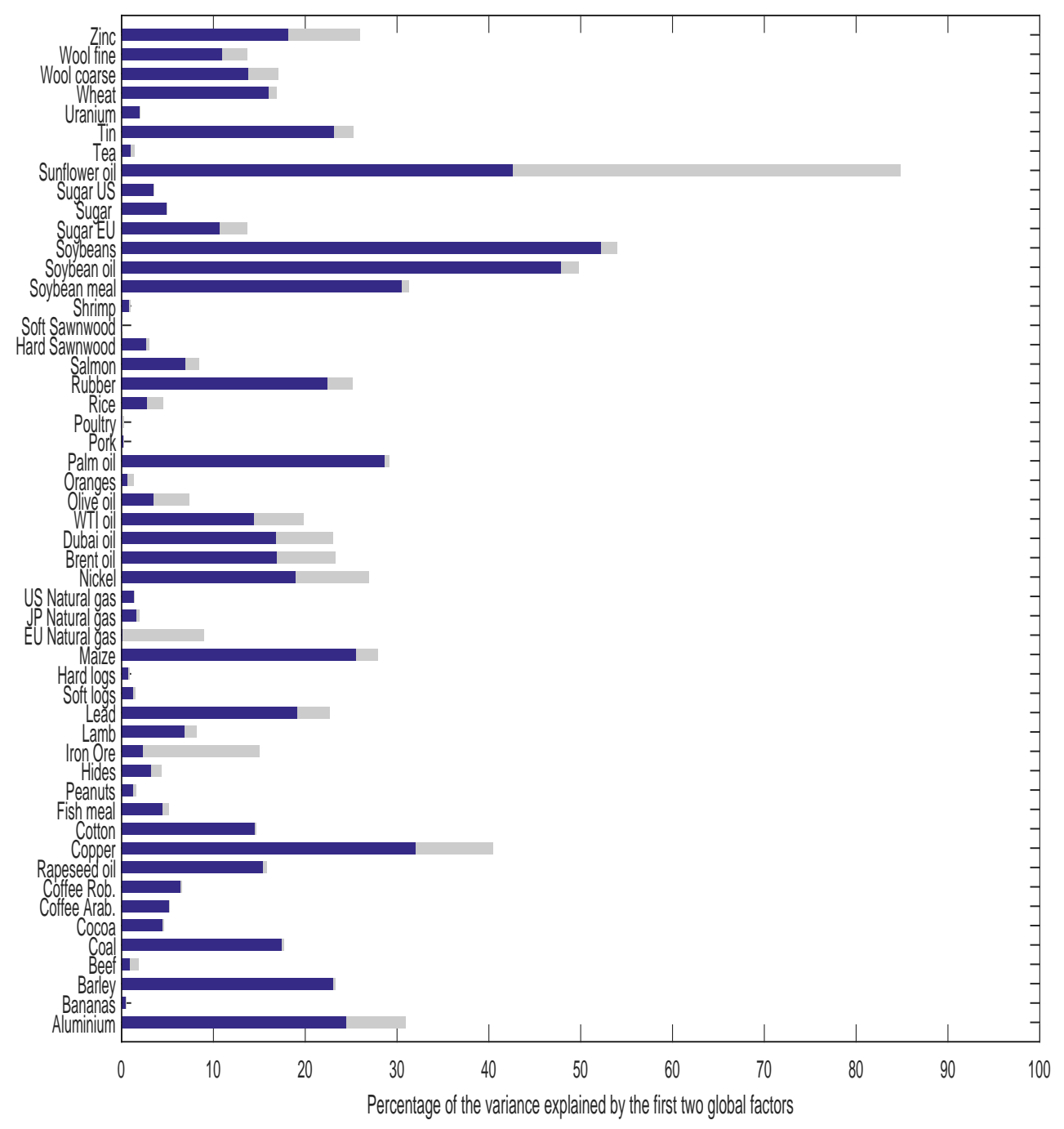


Figure 8: Block factors and weak common factors
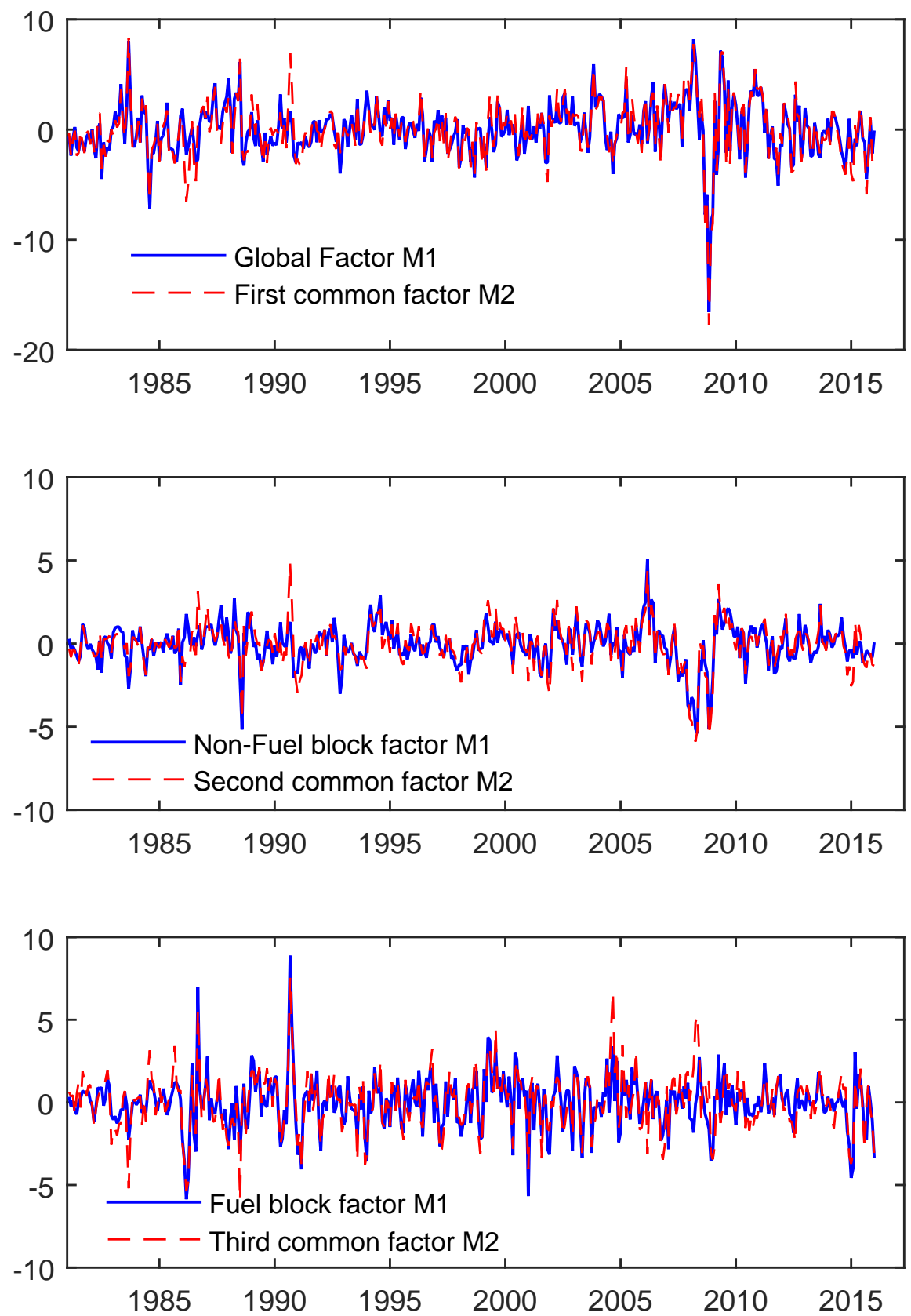

Note: The figure compares the the estimated global and block factors (Non-Fuel and Fuel) of our benchmark specification $\left(M_{1}\right)$ with the first three common factors extracted from a factor model without block structure $\left(M_{2}\right)$. 
Figure 9: Variance decomposition: sub-sample analysis

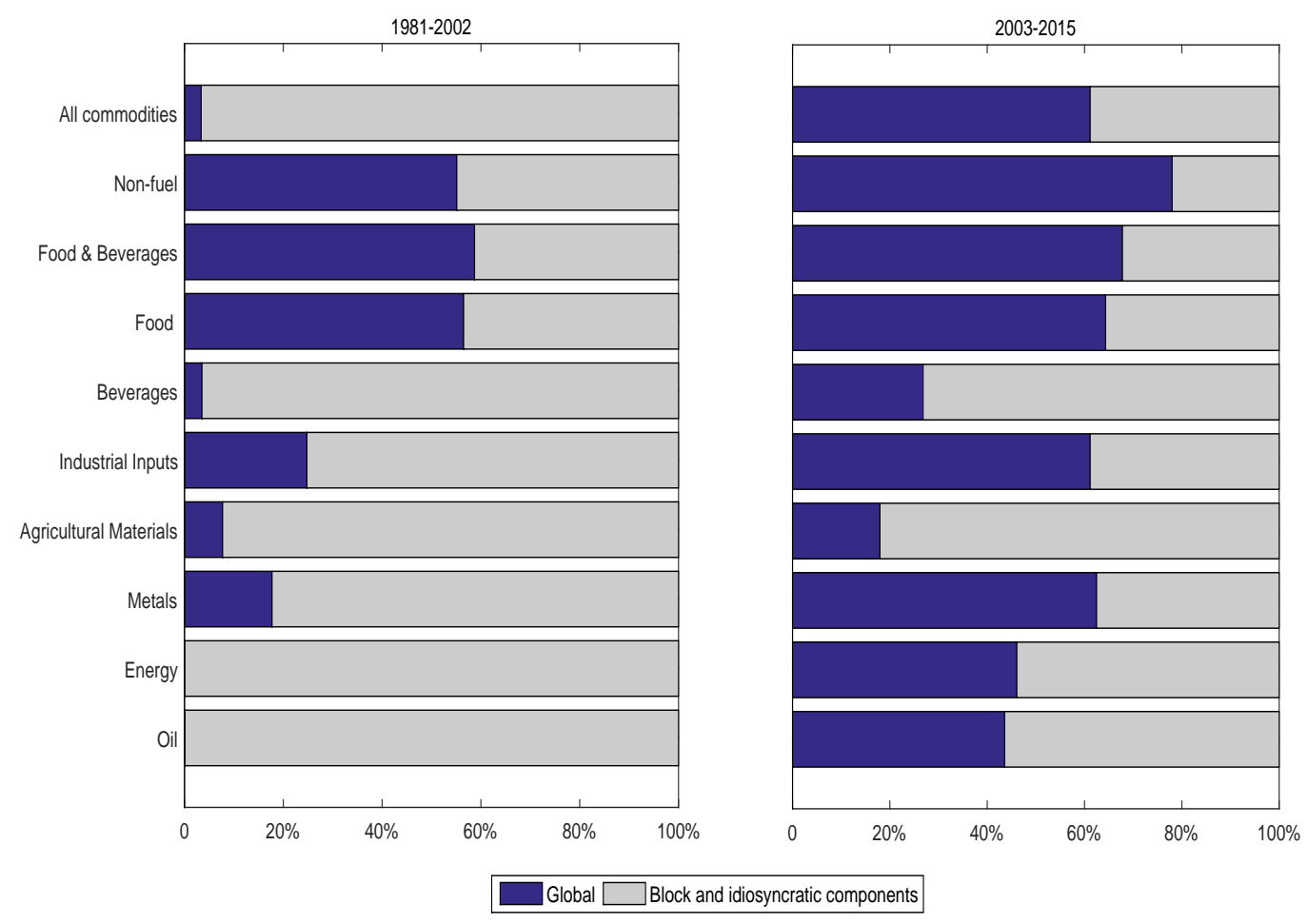

Note: The figure reports the variance decomposition of commodity price indices over two sub-samples. The share of the variance explained by the global factor is captured by the blue bar while the Grey bar is the percentage of the variance explained by block-specific and idiosyncratic components. The first subsample goes from Jan. 1981 to Dec. 2002 while the second goes from Jan. 2003 to Dec. 2015. 
Figure 10: Historical decompositions of commodity prices
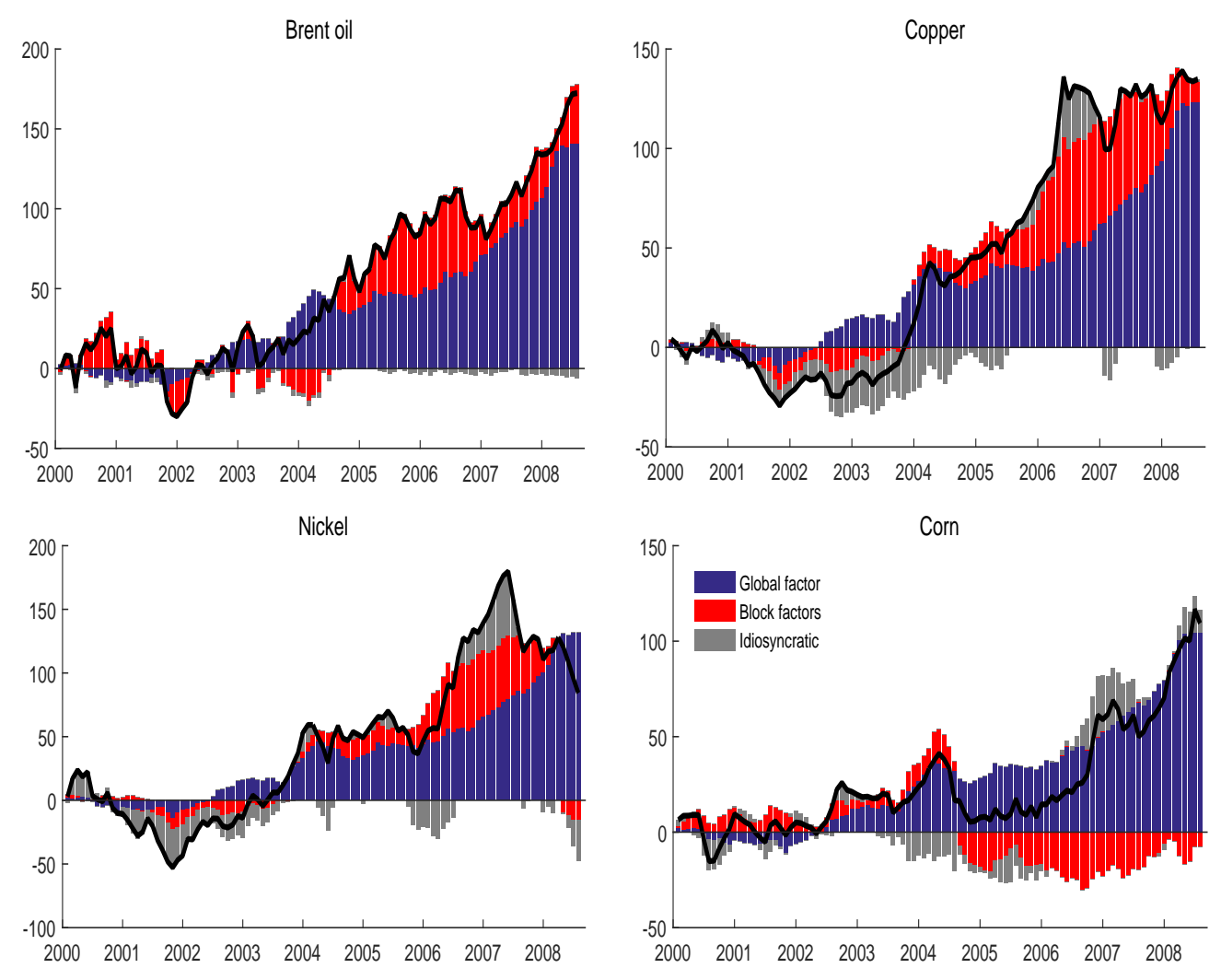

Note: The figure reports the historical decomposition of the price for a selected group of energy, metal and food commodities, showing the cumulative effects at each point in time of global (blue), block-specific (red) and idiosyncratic (Grey) shocks from January 2000 to July 2008. 
Figure 11: Historical decompositions of the price of oil in selected episodes
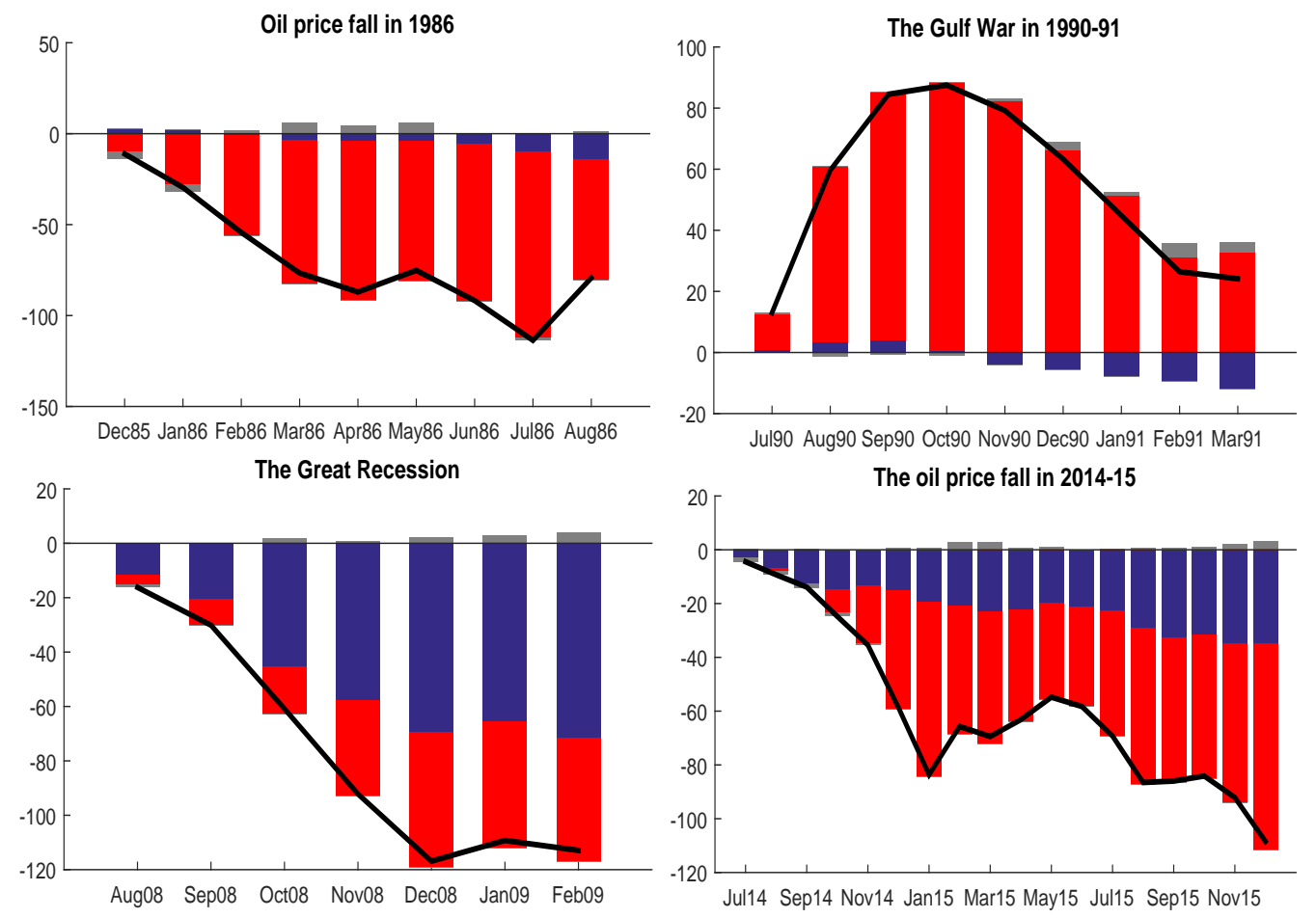

Note: The figure presents the historical decomposition of the price of oil, showing the cumulative effects at each point in time of global (blue), block-specific (red) and idiosyncratic shocks (Grey) during four historical episodes of large oil price variations. 
Figure 12: Time-varying predictability
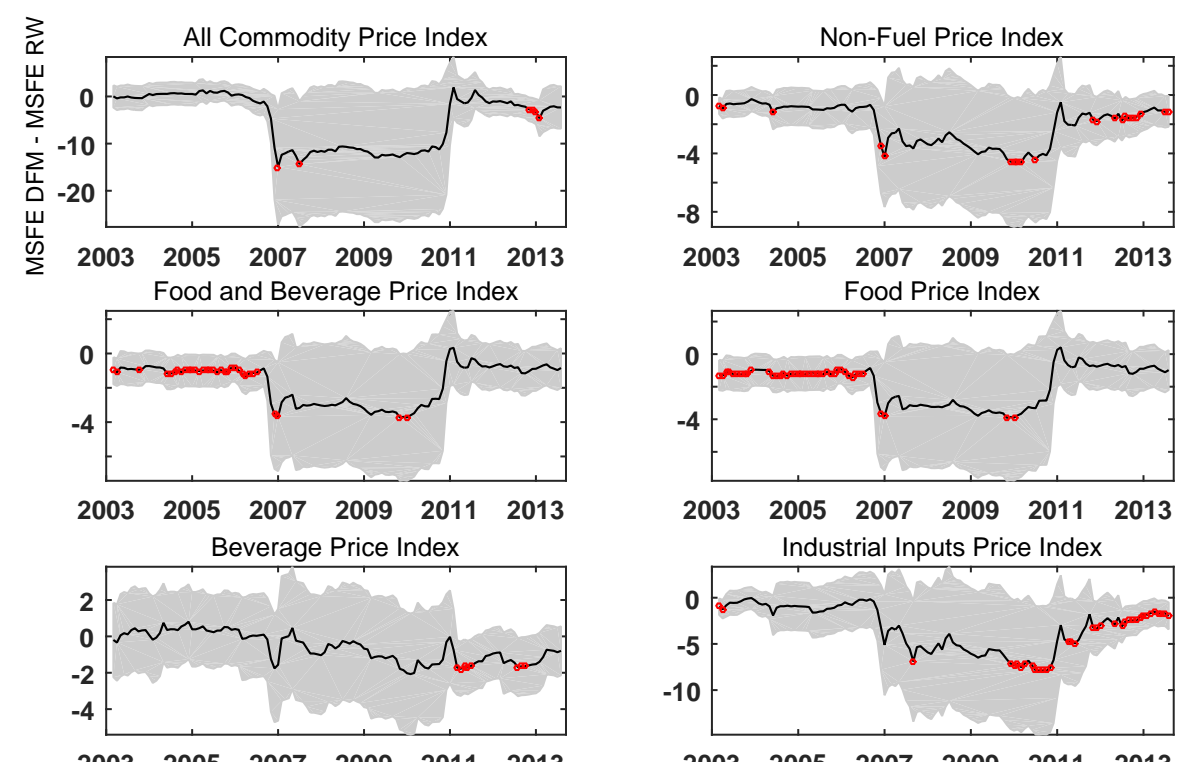

Industrial Inputs Price Index
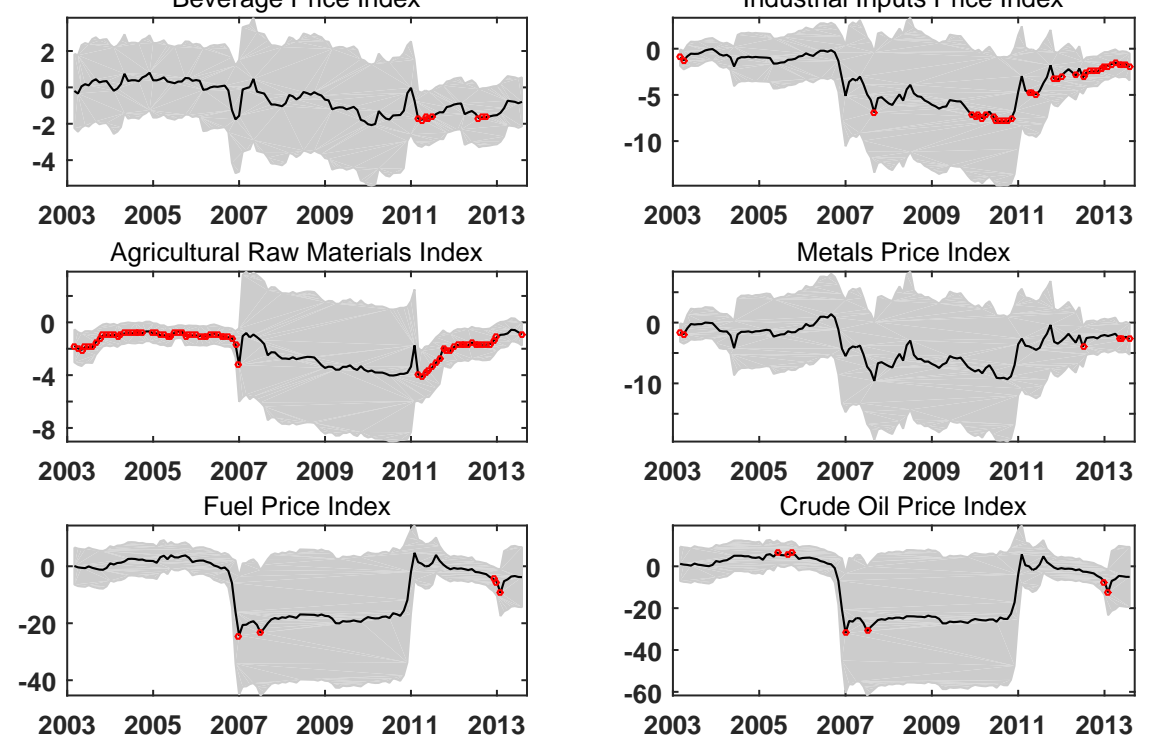

Note: The figure shows the difference between the MSFE of the factor model and the MSFE of the benchmark, smoothed over time with a centered rolling window spanning 4 years. A negative number indicates that the factor model has a higher predictive accuracy than the benchmark. The $90 \%$ confidence bands are represented by the shaded area and are derived from testing the null hypothesis of equal predictive accuracy at each point in time. Red circles indicate rejection of the hypothesis of equal predictive accuracy at the $5 \%$ level. 
Figure 13: The global factor extracted from real commodity prices
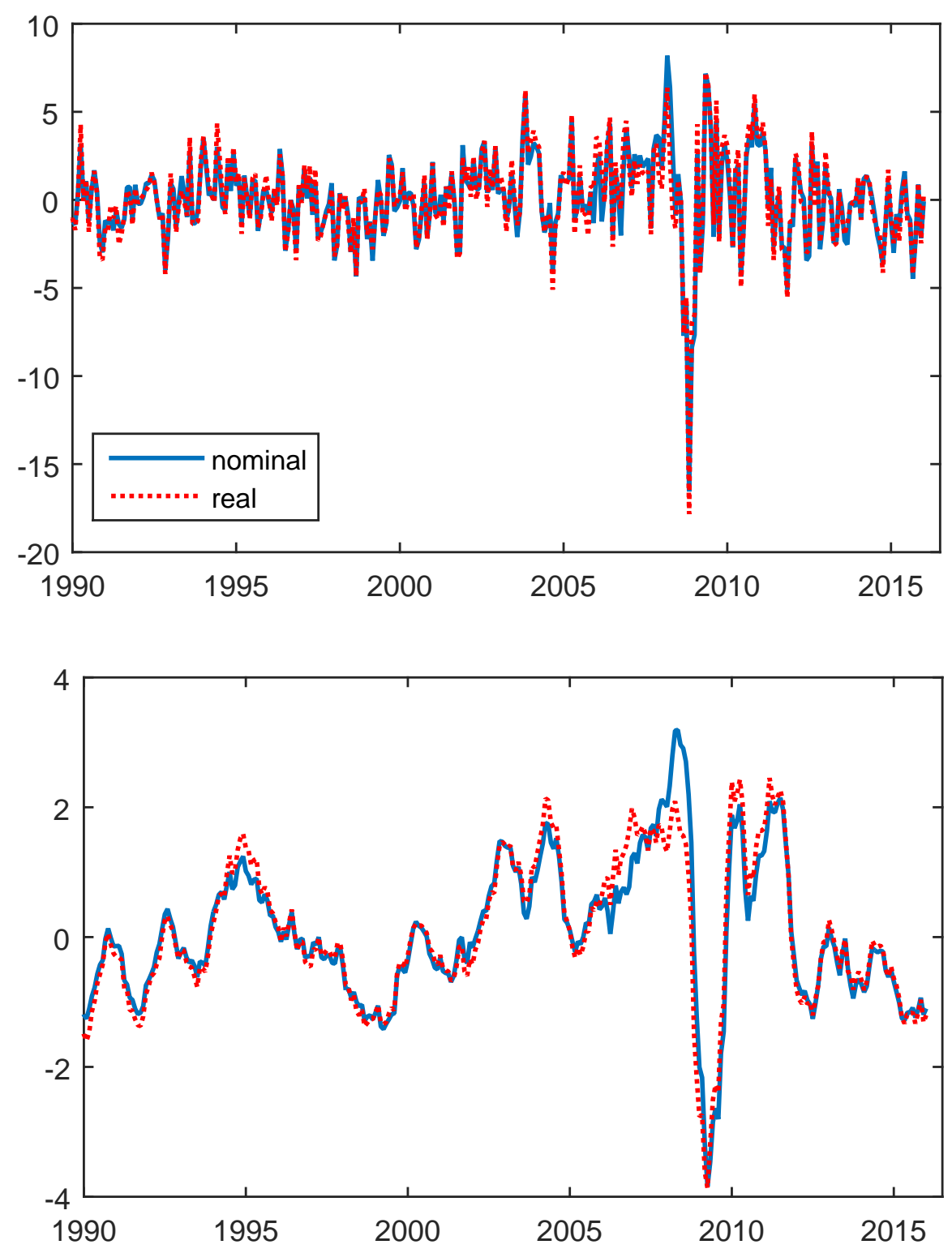

Note: The upper panel of the figure reports the estimated global factor extracted from real commodity prices (US CPI deflated). The lower panel reports the nominal and the real global factor expressed in year-on-year growth rates. 
Table 1: Structure of the database

\begin{tabular}{|c|c|c|c|c|}
\hline Global & Blocks & Sub-blocks & Groups & N. Series \\
\hline \multirow[t]{10}{*}{$\begin{array}{l}\text { All commodities } \\
\text { (PALLFNF) } \\
100.0\end{array}$} & & & & 52 \\
\hline & $\begin{array}{l}\text { Non-Fuel } \\
\text { (PNFUEL) } \\
36.9\end{array}$ & & & 45 \\
\hline & & $\begin{array}{c}\text { Food \& Beverages } \\
\text { (FFOBEV) } \\
18.5\end{array}$ & & 28 \\
\hline & & & $\begin{array}{c}\text { Food } \\
\text { (PFOOD) } \\
16.7\end{array}$ & 24 \\
\hline & & & $\begin{array}{c}\text { Beverages } \\
\text { (PBEV) } \\
1.8\end{array}$ & 4 \\
\hline & & $\begin{array}{l}\text { Industrial Inputs } \\
\qquad \begin{array}{c}\text { PINDU) } \\
18.4\end{array}\end{array}$ & & 17 \\
\hline & & & $\begin{array}{c}\text { Agricultural Raw Materials } \\
\text { (PAGR) } \\
7.7\end{array}$ & 9 \\
\hline & & & $\begin{array}{c}\text { Metals } \\
(\mathrm{PMET}) \\
10.7\end{array}$ & 8 \\
\hline & $\begin{array}{c}\text { Energy } \\
\text { (PNRG) }\end{array}$ & & & 7 \\
\hline & 63.1 & & $\begin{array}{c}\text { Oil } \\
(\text { POILAPSP) } \\
53.6\end{array}$ & 3 \\
\hline
\end{tabular}

Note: The data set includes one main index for all commodity prices and 9 sub-indices representing different levels of aggregation. The weights reported in the table represent the share of each sub-index in the overall index of commodity prices. 
Table 2: Data description

\begin{tabular}{|c|c|c|c|}
\hline Mnemonic & Unit & description & $\begin{array}{l}\text { IMF global commodity index } \\
\text { 2002-2004 weights }\end{array}$ \\
\hline PALLFNF & Index & All Commodity Price Index, $2005=100$, includes both Fuel and Non-Fuel & 100.0 \\
\hline PNFUEL & Index & Non-Fuel Price Index, $2005=100$, Food and Beverages and Industrial Inputs & 36.9 \\
\hline PFANDB & Index & Food and Beverage Price Index, $2005=100$, Food and Beverage & 18.5 \\
\hline PFOOD & Index & Food Price Index, $2005=100$, Cereal, Vegetable Oils, Meat, Seafood, Sugar, Bananas, Oranges & 16.7 \\
\hline PBEVE & Index & Beverage Price Index, 2005 = 100, Coffee, Tea, Cocoa & 1.8 \\
\hline PINDU & Index & Industrial Inputs Price Index, $2005=100$, Agricultural Raw Materials and Metals & 18.4 \\
\hline PRAWM & Index & Agricultural Raw Materials Index, $2005=100$, Timber, Cotton, Wool, Rubber, Hides & 7.7 \\
\hline PMETA & Index & Metals Price Index, $2005=100$, Copper, Aluminium, Iron Ore, Tin, Nickel, Zinc, Lead,Uranium & 10.7 \\
\hline PNRG & Index & Fuel (Energy) Index, $2005=100$, Crude oil , Natural Gas, Coal & 63.1 \\
\hline POILAPSP & Index & Crude Oil (petroleum), Price index, $2005=100$, simple average of Brent, WTI, Dubai Fateh & 53.6 \\
\hline PALUM & USD & Aluminium, 99.5\% minimum purity, LME spot price, CIF UK ports, USD per metric ton & 3.9 \\
\hline PBANSOP & USD & Bananas, Central American and Ecuador, FOB U.S. Ports, USD per metric ton & 0.4 \\
\hline PBARL & USD & Barley, Canadian no.1 Western Barley, spot price, USD per metric ton & 0.3 \\
\hline PBEEF & USD & Beef, Australian and New Zealand $85 \%$ lean fores, CIF U.S. import price, US cents per pound & 1.4 \\
\hline PCOALAU & USD & Coal, Australian thermal coal, 12,000- btu/pound, FOB Newcastle/Port Kembla, USD(metric ton) & 2.6 \\
\hline $\mathrm{PCOCO}$ & USD & Cocoa beans, Int. Cocoa Org. cash price, CIF US and European ports, USD per metric ton & 0.7 \\
\hline PCOFFOTM & USD & Coffee, Other Mild Arabicas, Int. Coffee Org. NY cash price, US cents per pound & 0.5 \\
\hline PCOFFROB & USD & Coffee, Robusta, Int. Coffee Org. NY cash price, US cents per pound & 0.4 \\
\hline PROIL & USD & Rapeseed oil, crude, fob Rotterdam, USD per metric ton & 0.3 \\
\hline PCOPP & USD & Copper, grade A cathode, LME spot price, CIF European ports, USD per metric ton & 2.8 \\
\hline PCOTTIND & USD & Cotton,Outlook 'A Index', Middling 1-3/32 inch staple, CIF Liverpool, US cents per pound & 0.7 \\
\hline PFISH & USD & Fishmeal, Peru Fish meal/pellets $65 \%$ protein, CIF, USD per metric ton & 0.2 \\
\hline PGNUTS & USD & Groundnuts (peanuts), $40 / 50$, cif Argentina, USD per metric ton & 0.2 \\
\hline PHIDE & USD & Hides, Heavy native steers, over 53 pounds, wholesale price, US, Chicago, US cents per pound & 2.6 \\
\hline PIORECR & USD & China import Iron Ore Fines 62\% FE spot (CFR Tianjin port), US dollars per metric ton & 1.3 \\
\hline PLAMB & USD & Lamb, frozen carcass Smithfield London, US cents per pound & 0.3 \\
\hline PLEAD & USD & Lead, $99.97 \%$ pure, LME spot price, CIF European Ports, USD per metric ton & 0.2 \\
\hline PLOGORE & USD & Soft Logs, Average Export price from the U.S. for Douglas Fir, USD per cubic meter & 0.4 \\
\hline PLOGSK & USD & Hard Logs, Best quality Malaysian meranti, import price Japan, USD per cubic meter & 0.4 \\
\hline PMAIZMT & USD & Maize (corn), U.S. No.2 Yellow, FOB Gulf of Mexico, U.S. price, USD per metric ton & 1.0 \\
\hline
\end{tabular}


PNGASEU USD Natural Gas, Russian Natural Gas border price in Germany, USD per thousands of cubic meters of gas

USD Natural Gas, Indonesian Liquefied Natural Gas in Japan, USD per cubic meter of liquid

USD Natural Gas, Henry Hub terminal in Louisiana, USD per thousands of cubic meters of gas

USD Nickel, melting grade, LME spot price, CIF European ports, USD per metric ton

USD Crude Oil (petroleum), Dated Brent, light blend 38 API, fob U.K., USD per barrel

POILDUB USD Oil; Dubai, medium, Fateh 32 API, fob Dubai Crude Oil, Dubai Fateh Fateh 32 API, USD per barrel

POILWTI

USD Crude Oil (petroleum), West Texas Intermediate 40 API, Midland Texas, USD per barrel

POLVOIL USD Olive Oil, extra virgin less than $1 \%$ free fatty acid, ex-tanker price U.K., USD per metric ton

PORANG

USD Oranges, miscellaneous oranges CIF French import price, USD per metric ton

PPOIL

USD Palm oil, Malaysia Palm Oil Futures (first contract forward) 4-5 percent FFA, USD per metric ton

PPORK

USD Swine (pork), 51-52\% lean Hogs, U.S. price, US cents per pound

PPOULT USD Poultry (chicken), Whole bird price, Ready-to-cook, whole, iced, Georgia, US cents per pound

PRICENPQ USD Rice, 5 percent broken milled white rice, Thailand nominal price quote, USD per metric ton

PRUBB

PSALM

USD

PSAWMAL USD Hard Sawnwood, Dark Red Meranti, select and better quality, C\&F U.K port, USD per cubic meter

PSAWORE

PSHRI

PSMEA

PSOIL

PSOYB

PSUGAEEC Soft Sawnwood, average export price of Douglas Fir, U.S. Price, USD per cubic meter

Shrimp, No.1 shell-on headless, 26-30 count per pound, Mexican origin, NY port, US cents-pound

Soybean Meal, Chicago Soybean Meal Futures Minimum 48 percent protein, USD per metric ton

USD Soybean Oil, Chicago Soybean Oil Futures exchange approved grades, USD per metric ton

USD Soybeans, U.S. soybeans, Chicago Soybean futures contract No. 2 yellow and par, USD per metric ton 1.2

PSUGAISA USD Sugar, Free Market, CSCE contract n.11, US cents a pound

USD

Sugar, U.S. import price, contract no.14 nearest futures position, US cents a pound

PSUNO

PTEA

USD Sunflower oil, Sunflower Oil, US export price from Gulf of Mexico, USD per metric ton

Tea, Mombasa, Kenya, Auction Price, US cents per kg, From July 1998, Best Pekoe Fannings

USD Tin, standard grade, LME spot price, USD per metric ton

PURAN

USD Uranium, NUEXCO, Restricted Price, Nuexco exchange spot, USD per pound 
Table 3: Model Selection

\begin{tabular}{cccccc}
\hline & \multicolumn{5}{c}{ Number of global factors } \\
\cline { 2 - 6 } & $r=1$ & $r=2$ & $r=3$ & $r=4$ & $r=5$ \\
\hline$I C^{*}$ & 11.77 & 11.92 & 12.07 & 12.26 & 12.41 \\
$\log (V)$ & 11.57 & 11.53 & 11.48 & 11.47 & 11.43 \\
\hline
\end{tabular}

Table 4: Variance decomposition of commodity indices

\begin{tabular}{|c|c|c|c|c|c|c|c|c|c|c|c|}
\hline Indices & Global & Non Fuel & $\begin{array}{c}\text { Food- } \\
\text { Bev. }\end{array}$ & Food & Bev. & $\begin{array}{c}\text { Ind. } \\
\text { Inputs }\end{array}$ & $\begin{array}{c}\text { Agric. } \\
\text { Raw Mat. }\end{array}$ & Metals & Fuel & Oil & Idiosyncratic \\
\hline All Commodities & 34.1 & 0.2 & 0.1 & 0 & 0 & 0 & 0 & 0.2 & 62.7 & 0 & 2.6 \\
\hline Non-Fuel & 68.6 & 3.1 & 1.7 & 0.1 & 0.5 & 0 & 0.8 & 3.7 & 0 & 0 & 21.3 \\
\hline Food and Beverages & 58.0 & 0 & 6.7 & 0.4 & 1.8 & 0 & 0 & 0 & 0 & 0 & 33.2 \\
\hline Food & 55.4 & 0.1 & 8.6 & 0.4 & 0 & 0 & 0 & 0 & 0 & 0 & 35.6 \\
\hline Beverages & 9.3 & 1.0 & 1.0 & 0 & 50.4 & 0 & 0 & 0 & 0 & 0 & 38.4 \\
\hline Industrial Inputs & 48.4 & 7.9 & 0 & 0 & 0 & 0.7 & 2.0 & 9.2 & 0 & 0 & 31.8 \\
\hline Agricultural Raw Materials & 10.5 & 1.4 & 0 & 0 & 0 & 31.2 & 8.3 & 0 & 0 & 0 & 48.6 \\
\hline Metals & 43.2 & 7.5 & 0 & 0 & 0 & 5.2 & 0 & 13.8 & 0 & 0 & 30.3 \\
\hline Energy & 19.9 & 0 & 0 & 0 & 0 & 0 & 0 & 0 & 78.1 & 0 & 2.0 \\
\hline Oil & 17.7 & 0 & 0 & 0 & 0 & 0 & 0 & 0 & 81.2 & 0 & 1.1 \\
\hline
\end{tabular}

Note: The table reports the model-based variance decomposition of commodity indices estimated over the sample January 1981 - December 2015. 
Table 5: Variance decomposition of commodity prices

\begin{tabular}{|c|c|c|c|c|c|c|c|c|c|c|c|}
\hline Commodity prices & Global & Non-Fuel & $\begin{array}{c}\text { Food- } \\
\text { Bev. }\end{array}$ & Food & Bev. & $\begin{array}{c}\text { Ind. } \\
\text { Inputs }\end{array}$ & $\begin{array}{c}\text { Agric. } \\
\text { Raw Mat. }\end{array}$ & Metals & Fuel & Oil & Idiosyncratic \\
\hline Aluminium & 23.6 & 7.4 & - & - & - & 3.4 & - & 0.5 & - & - & 65.1 \\
\hline Bananas & 0.4 & 0.3 & 1 & 1.2 & - & - & - & - & - & - & 96.9 \\
\hline Barley & 21.6 & 0.1 & 8 & 0.01 & - & - & - & - & - & - & 70.0 \\
\hline Beef & 0.8 & 1 & 0.5 & 0.4 & - & - & - & - & - & - & 97.7 \\
\hline Coal & 16.7 & - & - & - & - & - & - & - & 0.5 & - & 82.8 \\
\hline Cocoa & 4.4 & 0.3 & 2.4 & - & 4.0 & - & - & - & - & - & 88.9 \\
\hline Coffee Arabica & 5.2 & 0.7 & 0.1 & - & 67.3 & - & - & - & - & - & 26.7 \\
\hline Coffee Robusta & 6.4 & 0.5 & 0.1 & - & 70.1 & - & - & - & - & - & 22.9 \\
\hline Rapeseed Oil & 15.2 & 0.2 & 0.01 & 0.04 & - & - & - & - & - & - & 84.5 \\
\hline Copper & 30.8 & 9.4 & - & - & - & 1.4 & - & 6.2 & - & - & 52.2 \\
\hline Cotton & 13.7 & 0.4 & - & - & - & 0.2 & 2.1 & - & - & - & 83.6 \\
\hline Fish meal & 4.3 & 1 & 4.1 & 2.7 & - & - & - & - & - & - & 87.9 \\
\hline Peanuts & 1.1 & 0.8 & 20.3 & 8.0 & - & - & - & - & - & - & 69.8 \\
\hline Hides & 3.7 & 0.6 & - & - & - & 15.2 & 32.2 & - & - & - & 48.3 \\
\hline Iron ore & 2.6 & 11.1 & - & - & - & 3.3 & - & 77.0 & - & - & 6.0 \\
\hline Lamb & 6.7 & 1.1 & 9.3 & 0.2 & - & - & - & - & - & - & 82.7 \\
\hline Lead & 18.9 & 3.9 & - & - & - & 1.3 & - & 1.7 & - & - & 74.3 \\
\hline Soft logs & 1.1 & 0 & - & - & - & 3.3 & 1.1 & - & - & - & 94.2 \\
\hline Hard logs & 0.7 & 0 & - & - & - & 54.1 & 4.3 & - & - & - & 40.9 \\
\hline Maize & 23.0 & 0.9 & 21 & 0.4 & - & - & - & - & - & - & 55.0 \\
\hline EU Natural gas & 0.0 & - & - & - & - & - & - & - & 5.7 & - & 94.3 \\
\hline JP Natural gas & 1.3 & - & - & - & - & - & - & - & 0.4 & - & 98.3 \\
\hline US Natural gas & 1.6 & - & - & - & - & - & - & - & 1.0 & - & 97.4 \\
\hline Nickel & 19.2 & 10.1 & - & - & - & 1.8 & - & 0.8 & - & - & 68.1 \\
\hline Brent oil & 17.0 & - & - & - & - & - & - & - & 78.1 & 0.4 & 4.5 \\
\hline Dubai oil & 17.6 & - & - & - & - & - & - & - & 77.0 & 2.0 & 3.3 \\
\hline WTI oil & 16.1 & - & - & - & - & - & - & - & 77.2 & 5 & 1.3 \\
\hline Olive oil & 2.7 & 2.8 & 10.1 & 0.4 & - & - & - & - & - & - & 84.0 \\
\hline Oranges & 0.6 & 0 & 1 & 0.8 & - & - & - & - & - & - & 97.6 \\
\hline Palm oil & 28.7 & 0.3 & 2.3 & 0.05 & - & - & - & - & - & - & 68.6 \\
\hline Pork & 0.4 & 0.01 & 0.2 & 0.0 & - & - & - & - & - & - & 99.4 \\
\hline Poultry & 0.0 & 1 & 3 & 0.9 & - & - & - & - & - & - & 95.8 \\
\hline Rice & 2.7 & 1.6 & 3.4 & 0.02 & - & - & - & - & - & - & 92.4 \\
\hline Rubber & 22.1 & 2.8 & - & - & - & 0.01 & 0.7 & - & - & - & 74.4 \\
\hline Salmon & 6.0 & 1.5 & 2.8 & 0.06 & - & - & - & - & - & - & 89.7 \\
\hline Hard Sawnwood & 2.7 & 0.1 & - & - & - & 47.1 & 3.4 & - & - & - & 46.7 \\
\hline Soft Sawnwood & 0.0 & 0.0 & - & - & - & 3.1 & 0.9 & - & - & - & 96.0 \\
\hline Shrimp & 0.4 & 0.0 & 0.1 & 23.8 & - & - & - & - & - & - & 75.8 \\
\hline Soybean meal & 28.6 & 0.3 & 38 & 0.1 & - & - & - & - & - & - & 33.2 \\
\hline Soybean oil & 45.9 & 1.0 & 13 & 0.0 & - & - & - & - & - & - & 39.6 \\
\hline Soybeans & 48.7 & 0.8 & 38 & 0.2 & - & - & - & - & - & - & 12.2 \\
\hline EU sugar & 10.1 & 2.7 & 8.4 & 0.2 & - & - & - & - & - & - & 78.5 \\
\hline Sugar & 4.6 & 0.0 & 1 & 0.9 & - & - & - & - & - & - & 93.8 \\
\hline US sugar & 3.1 & 0 & 0.8 & 1.3 & - & - & - & - & - & - & 94.8 \\
\hline Sunflower oil & 40.1 & 43 & 9.9 & 0.1 & - & - & - & - & - & - & 6.5 \\
\hline Tea & 0.9 & 0.4 & 0.3 & - & 1 & - & - & - & - & - & 97.6 \\
\hline Tin & 21.9 & 2.0 & - & - & - & 0.4 & - & 2.0 & - & - & 73.7 \\
\hline Uranium & 1.8 & 0.0 & - & - & - & 0.01 & - & 1.1 & - & - & 97.1 \\
\hline Wheat & 17.1 & 0.2 & 10.1 & 0.5 & - & - & - & - & - & - & 72.0 \\
\hline Coarse wool & 13.0 & 4.1 & - & - & - & 1.0 & 2.1 & - & - & - & 79.9 \\
\hline Fine wool & 10.4 & 3 & - & - & - & 0.0 & 4.7 & - & - & - & 81.9 \\
\hline Zinc & 18.6 & 10.7 & - & - & - & 3.1 & - & 3.0 & - & - & 64.6 \\
\hline
\end{tabular}

Note: The table reports the model-based variance decomposition of commodity prices estimated over the sample January 1981 - December 2015. 
Table 6: Out-of-sample forecasting performance

\begin{tabular}{|c|c|c|c|c|c|c|}
\hline \multirow[b]{2}{*}{ Indices } & \multicolumn{3}{|c|}{$h=1$} & \multicolumn{3}{|c|}{$h=12$} \\
\hline & $\begin{array}{c}R M S E \\
\text { Benchmark }\end{array}$ & $\begin{array}{c}\text { Relative } \\
r=1\end{array}$ & $\begin{array}{l}M S E \\
r=2\end{array}$ & $\begin{array}{c}R M S E \\
\text { Benchmark }\end{array}$ & $\begin{array}{l}\text { Relative } \\
r=1\end{array}$ & $\begin{array}{l}M S E \\
r=\mathscr{2}\end{array}$ \\
\hline All commodities & 5.22 & $0.84^{*}$ & $0.85^{*}$ & 24.98 & 1.05 & 1.06 \\
\hline Non-fuel & 3.06 & $0.82^{* *}$ & $0.84^{*}$ & 15.21 & 1.11 & 1.11 \\
\hline Food and Beverages & 3.19 & $0.85^{* *}$ & $0.85^{* *}$ & 14.27 & $1.09^{* *}$ & $1.09^{* *}$ \\
\hline Food & 3.30 & $0.85^{* *}$ & $0.85^{* *}$ & 14.64 & $1.11^{* * *}$ & $1.11^{* * *}$ \\
\hline Beverages & 4.19 & 0.97 & 0.96 & 17.67 & 1.04 & 1.04 \\
\hline Industrial Inputs & 3.92 & $0.83^{* *}$ & 0.86 & 20.65 & 1.01 & 1.01 \\
\hline Agricultural Raw Materials & 3.12 & $0.81^{* *}$ & $0.81^{* *}$ & 14.71 & $0.98^{*}$ & 0.98 \\
\hline Metals & 5.05 & 0.88 & 0.95 & 26.15 & 1.04 & 1.04 \\
\hline Energy & 7.33 & 0.88 & 0.89 & 32.57 & 1.05 & 1.05 \\
\hline Oil & 8.55 & 0.88 & 0.89 & 35.68 & 1.01 & 1.01 \\
\hline
\end{tabular}

Note: The table shows the root mean forecast error (RMSE) of a benchmark model, i.e. a constant growth model and the MSE of the candidate forecasting model relative to the benchmark. A ratio smaller than 1 indicates that the factor model forecasts are on average more accurate. $(*),\left({ }^{* *}\right)$ and $\left({ }^{* * *}\right)$ indicate rejection of the null of equal predictive accuracy at the $10 \%, 5 \%$ and $1 \%$ level based on the Diebold and Mariano (1995) statistic. The model estimation is rolling using a fixed window of 20 years and the estimation starts in 2001:1. The evaluation period goes from 2001:2 to 2015:12. As robustness check, the table also displays the relative MSE for a model specification with two global factors. 
Table 7: Out-of-sample forecasting performance

\begin{tabular}{|c|c|c|c|c|c|c|}
\hline \multirow[b]{2}{*}{ Commodity prices } & \multicolumn{3}{|c|}{$h=1$} & \multicolumn{3}{|c|}{$h=12$} \\
\hline & $\begin{array}{c}R M S E \\
\text { Benchmark }\end{array}$ & $\begin{array}{c}\text { Relative } \\
r=1\end{array}$ & $\begin{array}{l}M S E \\
\quad r=2\end{array}$ & $\begin{array}{c}R M S E \\
\text { Benchmark }\end{array}$ & $\begin{array}{l}\text { Relative } \\
r=1\end{array}$ & $\begin{array}{r}M S E \\
r=2\end{array}$ \\
\hline Aluminium & 5.14 & 0.89 & 0.88 & 22.10 & 1.03 & 1.03 \\
\hline Bananas & 11.61 & 0.99 & 1.00 & 22.69 & 1.00 & 1.00 \\
\hline Barley & 6.49 & $0.89 *$ & 0.90 & 27.69 & 1.01 & 1.01 \\
\hline Beef & 4.52 & $0.94 *$ & $0.94 *$ & 16.08 & 1.00 & 1.00 \\
\hline Coal & 7.06 & $0.85 *$ & $0.85 *$ & 37.41 & 1.02 & 1.02 \\
\hline Cocoa & 6.05 & 0.98 & 0.98 & 23.34 & 1.04 & 1.04 \\
\hline Coffee Arabica & 6.51 & 0.99 & 0.99 & 28.24 & 0.98 & 0.98 \\
\hline Coffee Robusta & 5.91 & 0.98 & 0.98 & 26.51 & $0.97 * *$ & $0.97^{* *}$ \\
\hline Rapeseed Oil & 5.75 & $0.84 * *$ & $0.85 * *$ & 27.12 & 0.98 & 0.98 \\
\hline Copper & 7.05 & $0.82 *$ & $0.81 *$ & 32.63 & 1.05 & 1.05 \\
\hline Cotton & 6.32 & $0.83 * *$ & $0.83 * *$ & 32.30 & $0.98 *$ & $0.98 *$ \\
\hline Fish meal & 4.88 & $0.88 * * *$ & $0.87 * * *$ & 22.02 & 1.04 & 1.05 \\
\hline Peanuts & 4.91 & 1.09 & 1.10 & 27.16 & 1.06 & 1.06 \\
\hline Hides & 6.87 & 0.94 & 0.95 & 25.77 & 1.04 & 1.04 \\
\hline Iron ore & 8.77 & $1.88 * * *$ & $3.78 * * *$ & 35.50 & $3.12 * * *$ & $3.12 * * *$ \\
\hline Lamb & 3.44 & $0.88 * *$ & $0.87 * *$ & 17.87 & 1.00 & 1.00 \\
\hline Lead & 7.99 & 0.96 & 0.96 & 36.88 & 1.03 & 1.03 \\
\hline Soft logs & 6.64 & $0.86 * *$ & $0.86 * *$ & 13.24 & 1.02 & 1.02 \\
\hline Hard logs & 3.15 & $0.88 * * *$ & $0.88 * * *$ & 14.86 & 1.00 & 1.00 \\
\hline Maize & 6.30 & 0.96 & 0.97 & 27.03 & 1.02 & 1.03 \\
\hline EU Natural gas & 6.41 & 1.26 & $1.38 * *$ & 34.63 & 1.44 & 1.47 \\
\hline JP Natural gas & 7.13 & 0.98 & 0.98 & 29.33 & 1.00 & 1.00 \\
\hline US Natural gas & 13.22 & 1.00 & 1.00 & 44.65 & 1.01 & 1.01 \\
\hline Nickel & 8.99 & 0.92 & 0.91 & 42.67 & 1.05 & 1.05 \\
\hline Brent oil & 8.97 & 0.90 & 0.91 & 36.18 & 1.00 & 1.01 \\
\hline Dubai oil & 8.48 & 0.87 & 0.88 & 35.38 & 1.01 & 1.01 \\
\hline WTI oil & 8.78 & 0.89 & 0.90 & 36.07 & 1.01 & 1.02 \\
\hline Olive oil & 4.19 & $0.90 * *$ & $0.90 * *$ & 18.33 & 1.03 & 1.03 \\
\hline Oranges & 12.05 & 0.96 & 0.97 & 23.08 & $1.13 * * *$ & $1.13 * * *$ \\
\hline Palm oil & 7.83 & 0.92 & 0.92 & 32.21 & 1.04 & 1.04 \\
\hline Pork & 9.14 & 0.98 & 0.98 & 23.38 & 0.99 & 0.99 \\
\hline Poultry & 1.27 & $0.54 * * *$ & $0.54 * * *$ & 6.32 & 0.96 & 0.96 \\
\hline Rice & 5.92 & 0.81 & 0.81 & 25.86 & 1.01 & 1.01 \\
\hline Rubber & 8.27 & $0.89 *$ & $0.90 *$ & 37.20 & 1.00 & 1.00 \\
\hline Salmon & 7.03 & 0.92 & 0.93 & 22.26 & 1.04 & 1.04 \\
\hline Hard Sawnwood & 2.12 & 0.99 & 1.00 & 8.13 & $1.05^{* *}$ & $1.05 *$ \\
\hline Soft Sawnwood & 5.72 & 0.91 & 0.91 & 10.04 & $0.96^{* *}$ & $0.96 * *$ \\
\hline Shrimp & 5.00 & 0.98 & 0.99 & 20.98 & 1.00 & 1.00 \\
\hline Soybean meal & 7.10 & 0.93 & $0.92 *$ & 25.04 & 1.05 & 1.05 \\
\hline Soybean oil & 6.06 & 0.91 & 0.91 & 27.67 & 1.02 & 1.02 \\
\hline Soybeans & 6.51 & $0.91 *$ & $0.90 *$ & 26.61 & 1.03 & 1.03 \\
\hline EU sugar & 2.15 & 0.86 & $0.86 *$ & 9.67 & $1.06^{*}$ & $1.06 *$ \\
\hline Sugar & 7.71 & 0.97 & 0.97 & 30.31 & 1.04 & 1.04 \\
\hline US sugar & 3.53 & $0.88 * *$ & $0.88 * *$ & 17.71 & 0.97 & 0.97 \\
\hline Sunflower oil & 9.31 & 0.88 & 0.88 & 38.76 & 1.19 & 1.19 \\
\hline Tea & 7.08 & 0.99 & 0.99 & 19.23 & 1.05 & 1.05 \\
\hline Tin & 6.73 & $0.88^{* *}$ & $0.88 * *$ & 33.83 & 1.00 & 1.00 \\
\hline Uranium & 6.55 & 0.90 & 0.90 & 38.87 & 0.98 & 0.98 \\
\hline Wheat & 7.41 & 0.96 & 0.96 & 29.83 & $1.05^{* *}$ & $1.05 *$ \\
\hline Coarse wool & 5.80 & $0.91^{*}$ & $0.91 *$ & 28.39 & 1.03 & 1.03 \\
\hline Fine wool & 6.06 & $0.91 * *$ & $0.91 * *$ & 25.82 & 1.04 & 1.04 \\
\hline Zinc & 6.84 & 0.92 & 0.92 & 36.65 & 1.01 & 1.01 \\
\hline
\end{tabular}

Note: The table shows the root mean forecast error (RMSE) of a benchmark model, i.e. a constant growth model and the MSE of the candidate forecasting model relative to the benchmark. A ratio smaller than 1 indicates that the factor model forecasts are on average more accurate. $(*),(* *)$ and $(* * *)$ indicate rejection of the null of equal predictive accuracy at the $10 \%, 5 \%$ and $1 \%$ level based on the Diebold and Mariano (1995) statistic. The model estimation is rolling using a fixed window of 20 years and the estimation starts in 2001:1. The evaluation period goes from 2001:2 to 2015:12. As robustness check, the table also displays the relative MSE for a model specification with two global factors. 